\title{
Extremely High Frequency (EHF) Bands for Future Broadcast Satellite Services: Opportunities and Challenges
}

\author{
Claudio Sacchi, Senior Member, IEEE, Tommaso Rossi, Maurizio Murroni, Senior Member, IEEE, \\ Marina Ruggieri, Fellow, IEEE
}

\begin{abstract}
The exploitation of the bandwidth portions in the millimeter wave domain, namely: Extremely High Frequencies (EHFs) will open new perspectives to future satellite services, in particular for high quality TV broadcasting and multimedia content delivery. The present work aims at surveying the opportunities and challenges of EHF exploitation for broadband satellite applications in the broadcast framework. Theoretical capacity evaluation confirms that EHF satellite links can offer unprecedented data-rates, clearly superior than that actually provided by $\mathrm{Ku}$ and Ka-bands. However, some crucial issues are still to be solved, mainly in terms of mitigation of tropospheric propagation impairments and appropriate waveform design. Link and capacity analysis will be the basis for the investigation of future application scenarios of broadcast EHF satcoms, namely: HDTV and Ultra High-Definition TV (UHDTV), with particular emphasis to $4 \mathrm{~K}$ and $8 \mathrm{~K}$ video formats.
\end{abstract}

Index Terms - Next generation broadcast sat systems and standards, Future technologies and services for broadcasting, Extremely High Frequency (EHF), UHDTV.

\section{INTRODUCTION}

$\mathrm{S}$ ATELLITE communication is crucial to support the broadcasting industry; currently, satellite broadcast digital services are available worldwide and represent an important market for the broadcasting stakeholders in near future [1]. In the last decade, the standards for satellite broadcasting have been developed beside terrestrial ones deploying the current cuttingedge technologies [2-4]. Furthermore, the upcoming 5G scenario is focusing on the converged satellite and terrestrial networks [5]. One of the main appeal of the satellite broadcast technology is the availability of large amount of dedicated bandwidth if compared to terrestrial services. However, the increased demand of Ultra-High Definition TV (UHDTV) is raising new challenges in term of resource allocations also in the satellite market where $4 \mathrm{~K}$ and $8 \mathrm{~K}$ resolutions have been already tested and are being rolled out by Japan's public broadcaster (NHK) in 2018, in preparation for the Olympics Games 2020 in Tokyo. In this case, the 8K UHDTV (4320p), called Super HiVision [6], offers a frame resolution of $7680 \times 4320(33.2$

Paper submitted on September 4, 2018, revised on December 31, 2018.

A preliminary version of this paper has been published at the $12^{\text {th }}$ IEEE International Symposium on Broadband Multimedia Systems and Broadcasting (BMSB'17), Cagliari, Italy, June 7-9, 2017.

Claudio Sacchi is with the University of Trento, Dept. of Information Engineering and Computer Science (DISI), 38150, Trento, Italy and with the Consorzio Nazionale Interuniversitario per le Telecomunicazioni (CNIT), 43124, Parma (Italy), (e-mail: claudio.sacchi@unitn.it). megapixels), but it also offers a richer sound experience with 22.2 multi-channel sound, which has been developed by NHK Science \& Technical Research Laboratories. In this context, the bandwidth spaces in the Extremely High Frequency (EHF) portion of the electromagnetic spectrum (namely: 30-300 GHz), known also as millimeter Wave (mmWave) bands, will represent, in the opinion of many researchers, "the new broadband frontier" for satellite communications [7]. Such claim is supported by the long history of satellite communications that shows an incremental shift to higher carrier frequencies in order to find additional bandwidth resources. The exploitation of Kaband (18-30 GHz), dated since mid '90s, followed the exploitation of Ku-band (11-18 GHz), started in 1977 with the launch of Sirio satellite [8]. Nowadays, Ku-band is mainly reserved for satellite TV broadcasting, while Ka-band is used for satellite internetworking and other bandwidth-demanding services.

The further step in the exploration of novel bandwidth spaces concerns with the EHF portions beyond the Ka-band, namely: $\mathrm{Q} / \mathrm{V}$ band (about 40-75 GHz) and $\mathrm{W}$-band $(75-110 \mathrm{GHz})$. The current allocation (ITU - Region 1) of mmWave bands for satellite fixed and broadcasting services is shown in Tab. I:

TABLE I. ITU - REGION 1 EHF FREQUENCY ALLOCATION FOR SATELLITE SERVICES

\begin{tabular}{|l|l|l|}
\hline & Uplink & Downlink \\
\hline Q/V-band & $42.5-43.5 \mathrm{GHz}$ (fixed) & $37.5-42.5 \mathrm{GHz}$ (fixed) \\
& $47.2-50.2 \mathrm{GHz}$ (fixed) & $40.5-42-5 \mathrm{GHz}$ (broadcasting) \\
& $50.4-51.4 \mathrm{GHz}$ (fixed) & \\
\hline W-band & $81-86 \mathrm{GHz}$ (fixed) & $71-76 \mathrm{GHz}$ (fixed) \\
& & $74-76 \mathrm{GHz}$ (broadcasting) \\
\hline
\end{tabular}

The pioneering feasibility studies about EHF for satellite communications have been carried out in early 2000s in the framework of DAVID [9] and WAVE [10] experiments. The focus of these activities - where Italian Space Agency (ASI), University of Rome Tor Vergata and Politecnico di Milano, together with industrial actors and other academic research entities, involved in synergy - was mainly addressed to the W-

Tommaso Rossi and Marina Ruggieri are with the University of Rome "Tor Vergata", Department of Electronic Engineering and Interdepartmental Center for TeleInfrastructures (CTIF), Via del Politecnico 1, 00133, Rome, Italy (email: tommaso.rossi@uniroma2.it,ruggieri@uniroma2.it).

Maurizio Murroni is with University of Cagliari, Dept. of Electrical and Electronic Engineering (DIEE), Piazza d'Armi, 09123, Cagliari, Italy and with the Consorzio Nazionale Interuniversitario per le Telecomunicazioni (CNIT), 43124, Parma (Italy), (e-mail: murroni@diee.unica.it). 
band utilization. In parallel, European Space Agency (ESA) and ASI supported the Alphasat experiment, under which the "Aldo Paraboni" payload was set up and launched in July 2013 (and was operative in last months of 2013). Such a payload is used to perform $\mathrm{Q} / \mathrm{V}$ band propagation and communication experimental campaign. Some of the first scientific results of ALPHASAT measurement campaign can be found in [11], [12]. The opportunities offered by exploitation of EHF bandwidths for satellite communications are potentially very attractive in terms of available bandwidth, small antenna size and augmented capability of exploiting multi-beam satellites [13]. Therefore, we should expect that, in short time, EHF would enlarge spectrum availability as well as opportunities for new services.

The very large bandwidth availability of EHF domain will be a precious resource for future broadcast $\mathrm{TV}$, in particular for HDTV/UHDTV services. The offered opportunities are great but, on the other hand, the challenges to be faced are likewise significant. EHF satellite link budgets are power-constrained due to higher pathloss and critical tropospheric attenuations [7]. For this reason, the available on-board (uplink) and on-ground (downlink) carrier-to-noise ratio may be consistently decreased as compared to that achieved by transmission in lower spectrum portions (namely: Ku and Ka band). In [14], an estimation of the earth terminal size required to guarantee a given link availability for an EHF downlink is reported. For $97-98 \%$ availability a small earth terminal aperture of $7 \times 7 \mathrm{~cm}$. is enough, but to reach $99.8-99.9 \%$ availability, an aperture of $1.2 \mathrm{~m}$ is needed. In order to increase link availability and system capacity without increasing too much the terminal size and cost, physical layer solutions characterized by resilience against RF impairments (nonlinear amplification and phase noise) are strongly envisaged [15] together with efficient solutions for rain fading compensation, like, e.g., adaptive coding and modulation (ACM) [16] and site diversity [17], [18].

In the present work, architectures, opportunities and challenges of satellite EHF transmission will be analysed, and conveniently balanced, in the framework of the actual provision of emerging broadcast services to commercial customary. Substantially, this paper aims at exploring how the enormous EHF bandwidth spaces could be effectively used to support broadcasting services, transferring information at unprecedented rates. Many works have been published in the literature dealing with performance evaluation of broadband EHF satellite links in terms of bit-error-rate, raw capacity and link availability (see, e.g. [19], [20]). Fewer works have been published about possible applications of EHF satellite communications, mainly considering standard DVB-S2 [21] and HDTV services [22]. In this paper, the role of satellite EHF transmission in enhancing the customer satisfaction will be critically discussed, considering the perspective of future multi-gigabit/sec services like: Ultra High Definition TV (4K and 8K) [23].

The paper is structured as follows: in section II the development steps of EHF satellite communications systems are reviewed, moreover, the architectural implementation to support high throughput demanding broadcasting services is discussed. Section III reports the effects of tropospheric radio-propagation on EHF satellite link availability, along with possible countermeasures focusing, in particular, on site diversity techniques. In Section IV the detailed RF design issues concerning EHF satellite systems are reported. Section V is devoted to the analysis of Shannon capacity of single-beam and multi-beam EHF satellite systems. In Section VI the role of EHF in future UHDTV satellite broadcasting is discussed, while in Section VII paper conclusions are finally drawn.

\section{EHF SATELLITE COMMUNICATIONS: PAST AND ON-GOING EXPERIMENTAL MISSIONS}

The bandwidth portions beyond Ka-band were considered in the past for application scenarios in the field of radio astronomy [24], radar [25] and point-to-multipoint terrestrial transmissions [26]. EHF bands, in particular the $28 \mathrm{GHz}$ band, the $73.5 \mathrm{GHz}$ band and the $83.5 \mathrm{GHz}$ band are currently under considerations, for future broadband mobile $5 \mathrm{G}$ communications [27] and for the wireless backhaul of small cells [28]. The spectrum portion in the $26 \mathrm{GHz}$ band is a strong candidate to support future broadband applications in EU [29]. On the other hand, $60 \mathrm{GHz}$ band has been adopted by the forthcoming IEEE 802.11ad WLAN networking standard [30]. Other bands in the 66-76 $\mathrm{GHz}$ range are under discussion for additional indoor applications and specific use cases [31]. Besides for the abundance of spectral resources, satellite communications can take advantages from the exploitation of EHF bands, also for the following reasons [7]:

- High directivity and spatial resolution;

- Higher antenna gains and reduced side-lobe power, due to narrow beam-widths;

- Small antenna and equipment size;

- Reduced size of satellite and launch vehicles.

However, the actual exploitation of EHF for satellite communications requires to be carefully approached by means of intensive measurement campaigns to identify the actual behavior of the mmWave travelling through the troposphere. In the following of this section, we shall briefly mention the main experimental activities related to the transmission of EHF signals by real satellite links.

\section{A. ASI/ESA-Alphasat experiment: the "Aldo Paraboni" payload}

The starting point of this experiment was the long experience acquired by the Italian Space Agency (ASI) in the analysis and verification of $\mathrm{Ka}$-band and $\mathrm{Q} / \mathrm{V}$ band propagation in the framework of the Italsat F1 mission [32]. In 2006, ASI proposed to the European Space Agency (ESA) to host an experimental payload in $\mathrm{Q} / \mathrm{V}$ band aboard the Alphasat geosynchronous Earth orbit (GEO) satellite, successfully launched in July 2013. The installed Technology Demonstration Payload number 5 (TDP\#5) was named in honor of professor Aldo Paraboni (1940-2013) of Politecnico di Milano (Italy), pioneer of research about the use of high frequencies in satellite communications [33].

The Q/V band TDP\#5 antenna farm is shown in Fig.1; two self-standing payloads are present, namely,

- Communication experiment payload, aimed at designing, optimizing and testing the effectiveness of adaptive transmission schemes, i.e., Propagation Impairment Mitigation Techniques (PIMTs), over the $\mathrm{Q} / \mathrm{V}$ band satellite channel. Experimented PIMTs are ACM, uplink power control (UL-PC) and space diversity. Modulated signals are transmitted to the Earth stations located in Spino D'Adda (Italy), Tito Scalo (Italy) and Graz 
(Austria). The Principal Investigator of communication experiment is University of Rome Tor Vergata.

- Propagation experiment payload, whose main target is to transmit an unmodulated carrier over a European coverage to derive first and second-order statistics of tropospheric attenuation, including rain fading, cloud fading and scintillations. Other interesting measurements performed by the propagation experiment payload are related to the acquisition of sky-noise temperature and the study of the parameters measured during the concurrent communication experiment. The Principal Investigator of propagation experiments is Politecnico di Milano.

More details about the payload features and the measurement approach followed by the communication and propagation experiments can be found in [11], [12], [32].

\section{B. AEHF satellite constellation}

The Advanced Extreme High Frequency (AEHF) satellite program is a follow-up of US Milstar military satellite system [34]. AEHF has been launched in 2013 and embarks a $44 \mathrm{GHz}$ EHF uplink transmitter, while the downlink is transmitting in the SHF-band (20 GHz frequency). AEHF satellites use a large number of narrow spot beams directed towards the Earth to relay communications to and from users. Crosslinks between the satellites allow them to relay communications directly rather than via a ground station. The satellites are designed to provide jam-resistant communications with a low probability of interception. They incorporate frequency-hopping radio technology, as well as phased array antennas that can adapt their radiation patterns in order to block out potential sources of jamming [34].

The maximum user data rate supported by AEHF is $8.2 \mathrm{Mb} / \mathrm{s}$, allowing transmission of real-time videos, battlefield maps, targeting data etc., while the total capacity provided is $430 \mathrm{Mb} / \mathrm{s}$ [35].

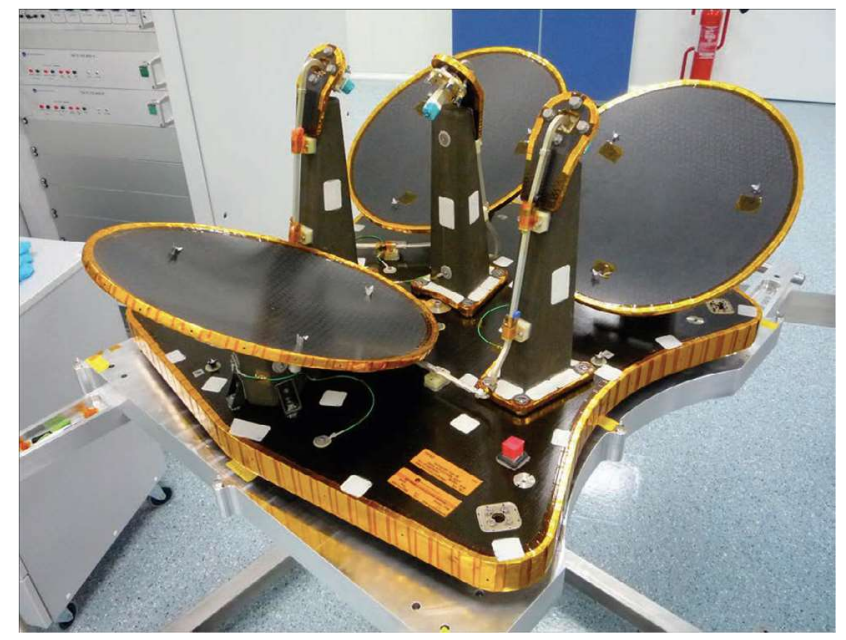

Fig. 1. The "Aldo Paraboni" payload antenna farm (courtesy of Space Engineering S.p.A).

\section{ASI-DAVID Data Collection Experiment (DCE)}

The Data and Video Interactive Distribution (DAVID) is a satellite mission of ASI [9] that completed the B phase in 2003. The C/D phase proposal has been delivered to ASI. The Data
Collection Experiment (DCE) of DAVID aims at proving the feasibility of high-speed data collection $(100 \mathrm{Mb} / \mathrm{s})$ from a content provider station via $84.5 \mathrm{GHz}$ W-band link. DAVID satellite is designed as a Sun-synchronous low-earth orbit satellite with orbit altitude of $570 \mathrm{~km}$, ensuring the re-visitation of the same site at the same hour every day. Details of the physical layer design of DAVID-DCE can be found in [20].

DAVID mission is currently on hold but in the near future, it is expected that DAVID mission could be carried on.

\section{WAVE}

W-band Analysis and Verification (WAVE) is an ASI project that can be regarded as the follow-up of DAVID. WAVE has been conceived to make possible the deployment of operative LEO/GEO satellites in the W-band for commercial services in 15-20 years [10][36]. The project, whose A2 phase has been successfully concluded in 2008 , includes two demonstrative missions and two pre-operative missions. The demonstrative missions are: Aero-WAVE, based on the use of High-Altitude Platforms, that will give preliminary results for the channel characterization and IKNOW, based on a small LEO, that will provide first-order statistics of satellite channel [10]. The two preoperative missions - one over LEO and the other one over GEO - will exploit the results achieved by demonstration missions in order to perform preliminary tests for operative use of W-band. Like DAVID, also WAVE is in a frozen status, waiting for Alphasat achievements.

\section{E. Architectures for EHF-supported Satellite Broadcasting Services}

To actually exploit the benefits provided by EHF (in particular beyond Ka-band) satellite systems for broadcasting applications, two main architectures could be used. The first one is a traditional architecture where the feeder-link is implemented using a single gateway and the users are illuminated by a single wide user beam (e.g. with full European coverage); in this context, "beyond Ka-band" frequencies can be used in an effective way only in the feeder-link because the large propagation impairments can be mitigated through site diversity techniques. On the other hand, at user level, these impairments will remain a major problem decreasing system availability to a level that is not compatible with the high requirements of the broadcasting service; hence, a backup user beam at lower frequencies should be used to restore the link in case of strong fading. For these reasons this kind of architecture is not suitable to capitalize the large spectrum availability provided by EHF bands and will not be further discussed in the rest of the paper.

The second architecture is based on the so-called High Throughput Satellite (HTS) systems. This architecture is implemented using multiple-beam user area coverage and multiple gateways, each one used to feed a subset of user-beams [37]; a typical HTS architecture is reported in figure 2. In order to boost system throughput, full frequency reuse is employed both for feeder and user link; in this last case, frequency reuse with different colors is implemented in order to mitigate interbeam interference. A typical implementation of this architecture with a European coverage foresees a Q/V-band feeder-link with 8 to 12 gateways (exploiting site diversity to increase system availability), and a Ka-band user-link with the 
coverage achieved through 80 to 120 beams exploiting four colors frequency reuse. This configuration allows to efficiently exploit both Q/V and Ka bands (maintaining the Ka-band technology at user level); a full capacity analysis for this architecture is reported in Section V. Future implementation of this kind of architecture can also exploit other frequency band as W-band and FSO (Free-Space Optics).

A low data rate return channel (via satellite or terrestrial) over each spot beam can be foreseen to implement propagation impairment mitigation techniques at user level so that to have the possibility to effectively counteract low system availability. In this context, the contents can be multicasted over user spot beams of few hundreds of $\mathrm{km}$ of diameter, opening the opportunity to support new and interesting services. As a matter of fact, this type of system can be used for DTH applications so that to deliver localized and regionalized contents, tailored on customers' requirements. This will provide to the broadcasters a very flexible way to distribute the content on customer base. This type of market is mainly based on fragmented audience and can be highly convenient for news gathering broadcasters or in regions where are present multiple languages (as Europe, India, etc.). DTH players that have to distribute contents in small countries (whose extension is one to few user spot beams) can benefit from this architecture. HTS architecture can be used also to support digital terrestrial television backbone network. Moreover, an integrated, multi user-beams and wide-beam architecture can be envisaged, where beam overlays so that to provide contents in the most flexible way.

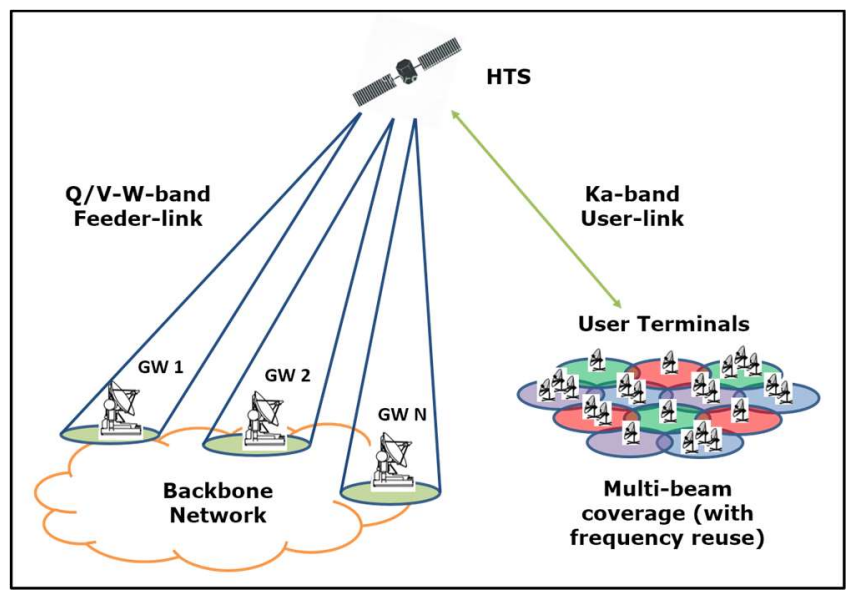

Fig. 2. Pictorial view of High Throughput Satellite (HTS) system architecture.

As discussed, using the "traditional" broadcasting architecture it is not possible to fully exploit the large bandwidth provided by EHF, because no frequency reuse is implemented; on the contrary, the HTS architecture is designed to take advantage of the peculiarities of EHF large spectrum availability and opens the opportunity to new and interesting markets for broadcasting applications, especially for HDTV/UHDTV ones (as is discussed in Section VI). For these reasons, in this paper the use of HTS system architecture capabilities will be analyzed for the provision of EHFsupported broadcasting services.

\section{F. Free-space optical (FSO) satellite links and hybrid EHF/FSO uplink}

FSO is nowadays a well consolidate technology for intersatellite link and deep-space communications [38], while its employment for multi-gigabit feeder links is still a hot research topic. Some recent experimental activities of ESA and NASA brought to the development of FSO satellite systems capable at supporting data rates up to $5.6 \mathrm{~Gb} / \mathrm{s}$ [39][40]. Thanks to Wavelength Division Multiplexing (WDM), it would be theoretically possible to boost terabit capacities on a single beam. The main issue of FSO-based feeder links is related to the intermittent availability, due to the severe impact of atmospheric phenomena. Indeed, cloud, fog, and rain can block the laser beam, definitely hindering detection and demodulation. The FSO solution is, therefore, an interesting alternative to radio transmission in the framework of bulk data upload and store-and-forward applications, where, differently than in broadcasting, the continuous service availability is not an issue. Anyway, a very recent work considers, at feasibility study level, an advanced broadband feeder link solution based on the seamless integration of FSO and EHF transmission [41]. The virtual switching from FSO to EHF link (and vice-versa) is decided on the basis of the propagation conditions and managed in software manner by a network orchestrator.

In the present work, the EHF solution for the feeder link of broadcast video content delivery systems is analyzed in details, as it is regarded as a potential baseline solution capable of guaranteeing a satisfactory service continuity in the near future. The SDN-based integration of FSO and EHF technology proposed by [41] may be regarded as a potential breakthrough in a longer view perspective.

\section{EHF TROPOSPHERIC RADIO PROPAGATION ISSUES AND POSSIBLE COUNTERMEASURES}

\section{A. Gaseous absorption}

As far as the gaseous absorption is concerned, two contributions should be taken into account: for EHF satellite connections oxygen $\left(\mathrm{O}_{2}\right)$ and water vapor $\left(\mathrm{H}_{2} \mathrm{O}\right)$ absorption. The effects of gaseous absorption are mainly limited to the troposphere, whose height depends on the latitude, namely: 20 $\mathrm{Km}$ close to tropics, $17 \mathrm{~km}$ at mid latitudes and $7 \mathrm{~km}$ in the Polar region. On the other hand, in the higher layer of the atmosphere, the density of absorbing gases becomes negligible. A detailed analysis of $\mathrm{O}_{2}$ and $\mathrm{H}_{2} \mathrm{O}$ absorption for long-range radio links is proposed and mathematically formalized in [42]. The numerical outcome of such analysis in the framework of the frequency bands used in satellite communications is shown in Fig.3, where the average tropospheric altitude of $15 \mathrm{~km}$ has been assumed and the other atmospheric parameters have been set according to [43], i.e.:

- Atmospheric temperature: $15^{\circ} \mathrm{C}$;

- Dry air pressure: $1013 \mathrm{hPa}$;

- Water vapor density: $7.5 \mathrm{~g} / \mathrm{m}^{3}$;

An elevation angle of $45^{\circ}$ has been considered in our test. A critical attenuation peak is observed in Fig.3 at $60 \mathrm{GHz}$ frequency, mainly due to $\mathrm{O}_{2}$ absorption. $\mathrm{Ku}$ and Ka-band bands generally exhibit very favorable gaseous attenuation values, 
whose local maximum of $4 \mathrm{~dB}$ is encountered at $22 \mathrm{GHz}$. In $\mathrm{Q} / \mathrm{V}$ band, the gaseous attenuation overall increases with the frequency, ranging from a minimum of $2.7 \mathrm{~dB}$, observed in correspondence of $37.5 \mathrm{GHz}$ to a maximum of $10 \mathrm{~dB}$, measured at $51.4 \mathrm{GHz}$. Such an attenuation increase is mainly involved by $\mathrm{H}_{2} \mathrm{O}$ absorption. However, the contribution of $\mathrm{O}_{2}$ absorption is significant as far as the critical threshold of $50 \mathrm{GHz}$ is trespassed. If $\mathrm{W}$-band transmission is considered, we can notice an almost constant gaseous attenuation of $6.5-7 \mathrm{~dB}$ due to water vapor. Indeed, the $\mathrm{O}_{2}$ absorption is overall negligible at these frequencies.

Results shown in Fig.3 evidence that gaseous absorption is not detrimental for EHF satellite transmissions, at least in the licensed bands, however it is not negligible, like in $\mathrm{Ku}$ and, partially, in Ka-band. So, such attenuation should be considered in the link budget by means of suitable SNR margins.

\section{B. Rain and cloud fading}

Rain fading is, for sure, the most critical tropospheric propagation issue in EHF satellite transmission. Indeed, the available models for rain fading prediction, like the ITU-R P.838-2 model [44], can only estimate a huger rain fading in EHF as compared to that measured at lower frequency bands.

More in details, the P838-2 model estimates the specific rain attenuation in $\mathrm{dB} / \mathrm{Km}$ by using the following power-law relationship:

$$
\gamma_{\text {rain }}=k R^{\alpha}[d B / K m]
$$

where: $R$ is the rainfall rate (in $\mathrm{mm} / \mathrm{h}$ ), $k$ and $\alpha$ are frequencydependent coefficients given in [44] (page 2, Tab. I, and page 4-5, Figs 1-4) for linear polarizations (horizontal and vertical) and horizontal paths for a frequency range between 1 and 400 GHz. The computation of $k$ and $\alpha$ for all path geometries is performed as follows [44]:

$$
\begin{gathered}
k=\left[k_{H}+k_{V}+\left(k_{H}-k_{V}\right) \cos ^{2} \theta \cos 2 \tau\right] / 2 \\
\alpha=\left[k_{H} \alpha_{H}+k_{V} \alpha_{V}+\left(k_{H} \alpha_{H}-k_{V} \alpha_{V}\right) \cos ^{2} \theta \cos 2 \tau\right] / 2 k
\end{gathered}
$$

$k_{h}, k_{v}, \alpha_{h}$ and $\alpha_{v}$ being, respectively, the coefficients of (1) given for horizontal and vertical polarizations, $\theta$ the path elevation angle and $\tau$ the polarization tilt angle relative to the horizontal. In order to derive the effective rain attenuation, we need to compute also the rain height. To this aim, the ITU recommendation ITU-R P.839-4 [45] suggests the following formulation for the mean annual rain height above mean sea level:

$$
h_{\text {rain }}=h_{0}+0.36[\mathrm{Km}]
$$

where $h_{0}$ is the 0 degree isotherm height shown, for different longitudes and latitudes, in the digital map annexed to [45].

However, such predictions are still not supported by experimental data acquired in-orbit by any payload. The "Aldo Paraboni" payload propagation experiment is collecting data about $\mathrm{Q} / \mathrm{V}$-band transmission since about four years. But, in order to have reliable and stable data that are needed to derive a credible experimental statistical distribution model of rain attenuation, additional years of in-orbit measurements are required. About, W-band satellite propagation, no experimental data are currently available and will be even available shortly.
Despite the various pre-competitive studies carried out in the recent past, the in-orbit launch of a large W-band GEO scientific payload is not foreseen, at least in this decade. In this framework, ESA is founding the development of a LEO cubesat for a preliminary experimental campaign to collect W-band tropospheric propagation data.

In Fig. 4a, some exemplary plots about rain fading statistical distribution, derived by using the ITU-R P.838-2 model [44], have been shown. The probability values reported on the abscissae are those for which the attenuation values reported on the ordinate axis of the plots are exceeded. Experimental data about rainfall intensity (measured in $\mathrm{mm} / \mathrm{h}$ ) have been collected at Conca del Fucino site (Italy) [46]; the complementary cumulative distribution of these data is reported in Fig. 4b. In such examples, the angles $\theta$ and $\tau$ have been both imposed equal to $45^{\circ}$. It is evident from Fig. $4 \mathrm{a}$ that the rain attenuation of $\mathrm{Q} / \mathrm{V}$ and $\mathrm{W}$-band is considerably higher than that estimated at lower frequencies. A rain attenuation of $29 \mathrm{~dB}$ is exceeded with a probability of $10^{-3}$ (corresponding to a $99.9 \%$ availability), when a signal is transmitted at $83.5 \mathrm{GHz}$. For the same probability, the attenuation decreases to $21 \mathrm{~dB}$ for $47 \mathrm{GHz}$ frequency. The corresponding values for $28.75 \mathrm{GHz}$ and 17 $\mathrm{GHz}$ frequencies are $10 \mathrm{~dB}$ and $4 \mathrm{~dB}$ respectively. These numbers confirm that specific countermeasures against rain fading should be considered in order to increase EHF link availability.

At "beyond Ka-band" frequencies, cloud attenuation has to be carefully investigated too, being associated with the impact of suspended droplets of liquid water or ice. This attenuation has an impact on the EM transmission because it can reach units of $\mathrm{dB}$, on the other hand, ITU-R P.840-7 models [47] can be used to estimate it and this impairment is in general managed through a margin in the link budget calculation. As an example, for an atmospheric temperature of $20^{\circ} \mathrm{C}$ and a cloud liquid water density of $0.5 \mathrm{~g} / \mathrm{m}^{3}$, cloud attenuation is about 0.22 $\mathrm{dB} / \mathrm{km}, 0.41 \mathrm{~dB} / \mathrm{km}, 0.61 \mathrm{~dB} / \mathrm{km}, 1.15 \mathrm{~dB} / \mathrm{Km}, 1.45 \mathrm{~dB} / \mathrm{km}$ and $1.75 \mathrm{~dB} / \mathrm{km}$ for $30 \mathrm{GHz}, 40 \mathrm{GHz}, 50 \mathrm{GHz}, 70 \mathrm{GHz}, 80 \mathrm{GHz}$ and $90 \mathrm{GHz}$, respectively.

\section{Tropospheric Scintillation}

Tropospheric scintillation is another source of impairments for EHF; in particular, for $\mathrm{Q} / \mathrm{V}$ and $\mathrm{W}$ bands scintillations could generate very fast signal variation, with an order of $\mathrm{dB}$ units [48], that cannot be tracked; this could lead to an instability of the techniques used to mitigate propagation impairments. As a matter of fact, some techniques based on hysteresis should be used to avoid frequent variation of transmission schemes due to scintillations. One example is the adaptive coding and modulation (ACM) with a hysteresis-based control loop, an option suggested also by DVB-S2/DVB-S2X standards [49], [50].

\section{Countermeasures against tropospheric impairments}

In the perspective of the future licensing of other mm-wave bandwidths, the use of EHF may increase substantially the available capacity of a geostationary satellite link, provided that some appropriate countermeasures against rain attenuation will be studied. In the literature, adaptive coding and modulation (ACM) schemes have been considered with optimized thresholds and precoding techniques aimed at extending the link 
availability also in case of rain events [21], [51]. ACM is generally used to mitigate user link fading; as an example, DVBS2X [48], with a huge set of ModCods (modulation and coding modes), small roll-off factors (down to $5 \%$ ) and the support to very low $\mathrm{SNR}$, is able to manage a fade dynamic of about $30 \mathrm{~dB}$ (from $-10 \mathrm{~dB}$ SNR up to $20 \mathrm{~dB}$ SNR). As a matter of fact, currently very-low SNR operating points and very high modulation orders are not covered in the DVB-S2X broadcasting profile, but, if the exploitation of EHF for broadcasting services would become widespread, the standard might be modified if these additional modulations and coding modes can bring substantial improvement to these services.

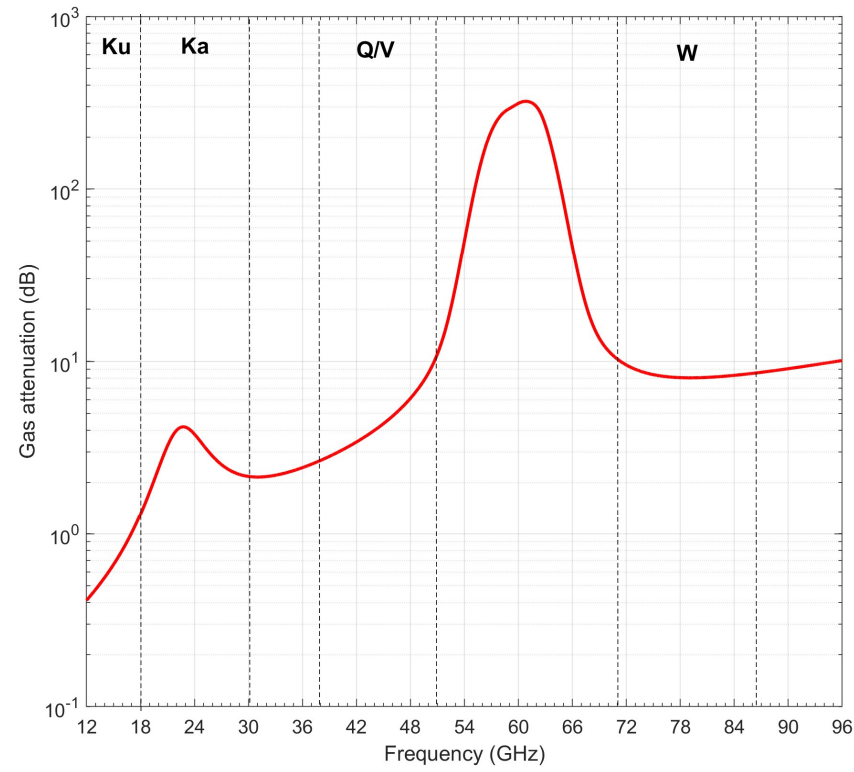

Fig. 3. Total gaseous absorption $\left(\mathrm{O}_{2}+\mathrm{H}_{2} \mathrm{O}\right)$ vs. carrier frequency in the different bandwidths considered for satellite communications (average troposheric height: $15 \mathrm{Km}$, elevation angle $45^{\circ}$ )

It has to be underlined that, DVB-S2X ModCod operative thresholds are provided for AWGN channel, hence, it is quite important to identify proper implementation margin required on top of the SNR requirements in order to take into account the real transmission channel. Recent experimental activities in Q/V-band demonstrated that the overall ACM implementation margin could be quite small, about 1.5-2 dB [12]. Slightly higher implementation margins may be required by $\mathrm{W}$-band connection due to the higher amount of phase noise [19][22].

Currently ACM is not used for broadcasting services but the use of such technique could be foreseen for EHF satellite broadcasting services based on HTS architecture described in Section II.E. In this framework, the user beams can be very small, few hundreds of $\mathrm{km}$ or even lower (especially if the userlink frequencies are beyond Ka-band), and ACM can be controlled by a single receiving station in the beam coverage. This station is part of the service provider architecture and can use different metrics as received SNR, weather forecast, beacon power level, etc. to select the most suitable modulation and coding (MODCOC) for the full beam coverage. This information is provided to the transmitting hub though a return channel (satellite or terrestrial). This approach is not effective to track rain attenuation, due to the small scale of correlation (tens of $\mathrm{km}$ ) but could be effective to counteract cloud attenuation that for EHF has a higher scale of correlation. With this strategy ACM MODCOD is selected on the basis of the "average" or "worst" (depending on the transmission protection requirements) tropospheric attenuation over the full user beam coverage and not on every single user channel condition but it can anyway increase the overall system capacity.

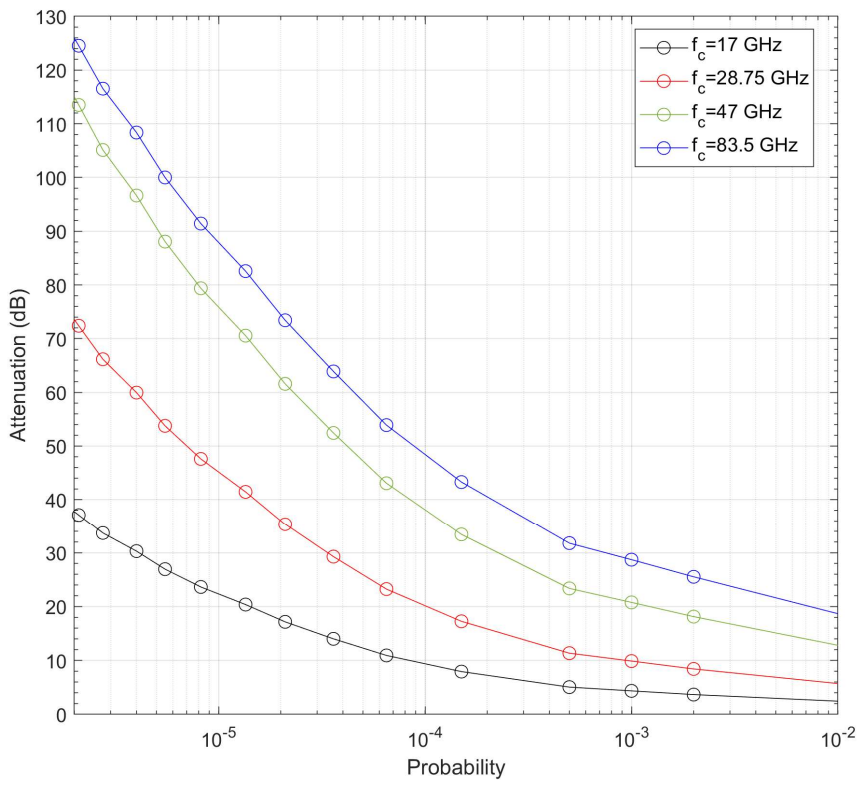

(a)

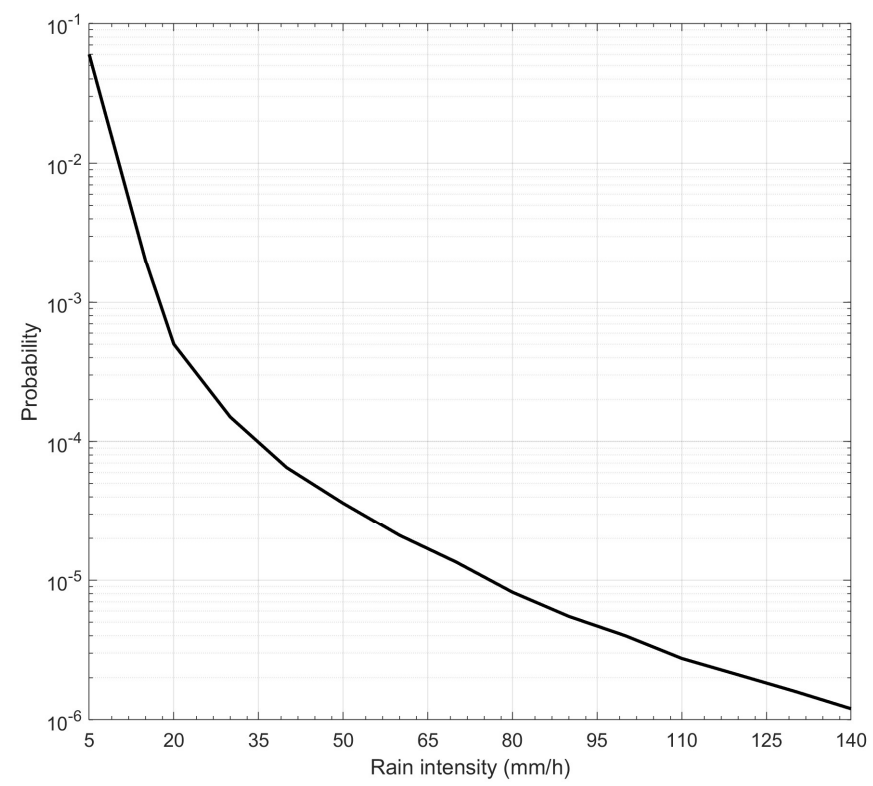

(b)

Fig. 4. (a) Rain attenuation vs. probability derived from the ITU-R P.838-2 model for the different frequency bands. Experimental data about cumulative statistical distribution of rainfall intensity related to the site of Conca del Fucino (Italy), taken by [46], are shown in (b).

For what concerns mitigation techniques for the feeder link, uplink power control can be used together with site diversity techniques as "smart gateways" (SG). Smart gateways have been pointed out in [12] and [17] as one of the enabling technologies of future EHF terabit satellites. In its more 
frequent implementation, SG diversity is based on a pool of $N$ active gateways together with $P$ cold ones; the latter are activated when other GWs experience an outage condition. The gateways are interconnected by means of a terrestrial fiber network and each of them is able at predicting the link outage due to some rain event; a scheme of SG architecture is reported in Fig. 5. In the case of a gateway experiencing outage or reduced capacity, some or all data traffic can be re-directed terrestrially to any one of the remaining gateways inside the pool that has some spare capacity to be allocated. SG is more efficient than classical site diversity, being not based on the full redundancy of all the GWs; this reduces the cost of the ground segment that has a large impact on the overall High Throughput Satellite system cost.

It has to be outlined that, to support smart-gateway, a high level of reconfiguration on the satellite payload is required, this increases the complexity of current HTS systems. As a matter of fact, the payload should guarantee the possibility to illuminate the same user beams from multiple GWs, using an on-board fully reconfigurable switching matrix. On the other hand, the results provided by smart gateways in terms of capacity improvement, even in case of huge rainfall events, look really impressive [17], [18], [20]. When EHFs are used, smart gateway is mandatory to reach the high feeder link availability required by broadcasting services and broadband user access services (higher than 99.5\%) maintaining a reasonable margin in the feeder link budget.

As shown in Fig. 4 (a), the rain fading margin needed to ensure $99.9 \%$ availability is $21 \mathrm{~dB}$ and $29 \mathrm{~dB}$ for $\mathrm{Q} / \mathrm{V}$ band and $\mathrm{W}-$ band respectively. The aforesaid margins are clearly unaffordable in intrinsically power-constrained link budgets. In [20] it is analyzed how diversity gain obtained by the smart gateway techniques could reach tens of $\mathrm{dB}$; some results are presented in Fig. 6 for Q/V-band satellite link $(50 \mathrm{GHz})$, where single CCDF of 6 sites in Europe are reported together with CCDF of two smart gateways implementation, the GEO satellite longitude is $9^{\circ}$ east; in particular, blue and green solid lines are related to the use of SG architecture with 4 and 6 sites respectively.

It is interesting to identify the diversity gain introduced by this technique, that is the difference between the attenuation not exceeded for a specific percentage of time on single sites and the one of SG. As an example, for $99.9 \%$ of time, the diversity gain is about $15 \mathrm{~dB}$ and $18 \mathrm{~dB}$ when 4 and 6 sites in SG configuration are used respectively. Such a gain should be theoretically obtained at the price of increasing the global system bandwidth occupation, as the satellite beams should use different frequency/time slots in order to broadcast the same content to the various gateways. In order to improve the spectral efficiency, avoiding the use of excess bandwidth, frequency reuse could be considered as alternative. In such a case, the price to be paid is in terms of crosstalk that may definitely decrease the overall system capacity. In the next sections, we shall focus on the impact of crosstalk on multibeam satellite link capacity. Other critical issues to be still addressed are related to the real-time fading detection, the optimization of gateway resources and the latencies involved by the rerouting of huge amount of traffic over wired terrestrial links.

Despite these technical uncertainties, tropospheric mitigation techniques can be very effective and improve the capacity that can be supported by W-band and Q/V-band channels over rain fading conditions.

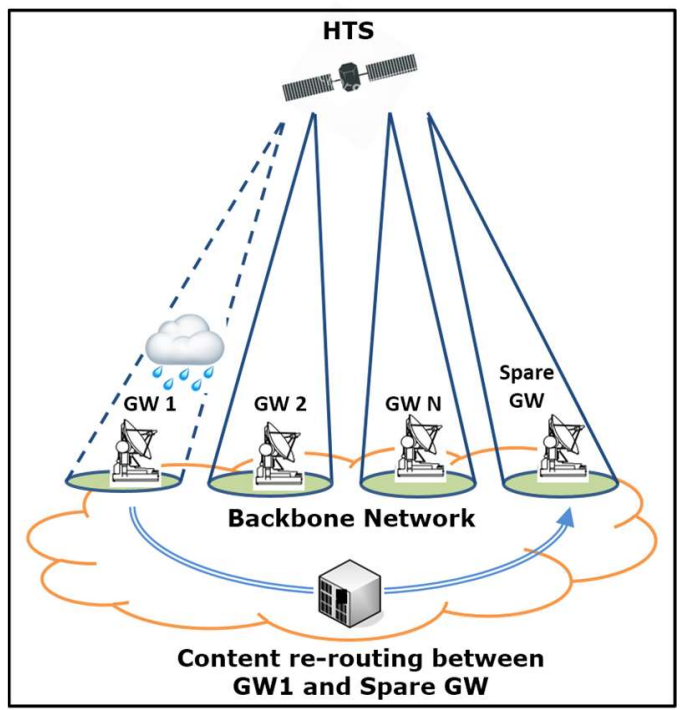

Fig. 5. Smart gateway diversity for feeder-link of EHF satellite broadcasting systems.

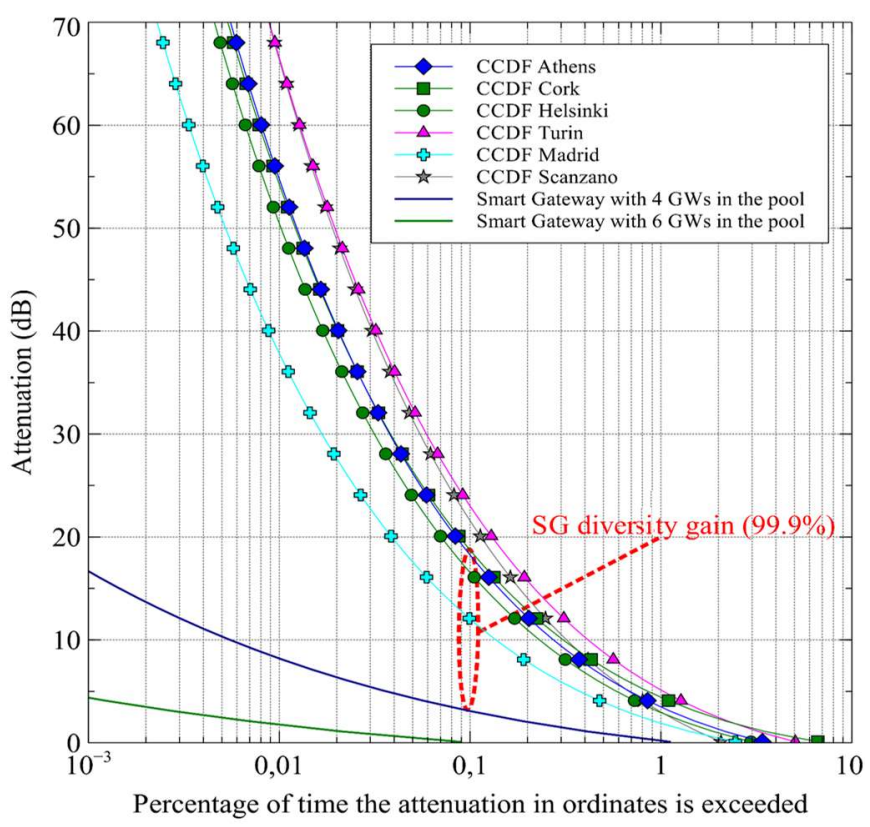

Fig. 6. Example of smart gateway diversity gain in Q/V-band.

\section{RF CHARACTERIZATION OF EHF SATELLITE SYSTEMS: IMPAIRMENTS AND POSSIBLE COUNTERMEASURES}

As stated in [15], EHF satellite link performance may be limited by some significant RF impairments that configure a "dirty RF environment". Such impairments can be listed as follows:

- High depointing losses, also noticed for very small pointing mismatch;

- Nonlinear amplification;

- $\quad$ Phase noise.

In the rest of this subsection, we shall analyze such impairments along with their effects on the overall link capacity. 


\section{A. Depointing loss}

It is known that, for a fixed diameter, high-frequency earthstation antennas are characterized by higher gain along the boresight, as shown in the subsequent equation,

$$
G_{e s}=9.94+10 \log _{10} \eta_{e s}+20 \log _{10}\left(D_{e s} \cdot f_{c} / c\right)(d B)
$$

where: $f_{c}$ is the carrier frequency, expressed in $\mathrm{Hz}, c$ is the speed of the light $\left(3 \times 10^{8} \mathrm{~m} / \mathrm{sec}.\right), \eta_{e s}<1$ is the equivalent antenna surface efficiency, also including all the structural losses, and $D_{e s}$ is the earth station antenna diameter. In Fig.7, the plots of $G_{e s}$ vs. $D_{e s}$ with $\eta_{e s}=0.7$ have been shown for the different bands currently in use and that will be used for satellite communications. It is clear that $G_{e s}$ increases with $D_{e s}$, but also with the transmission frequency. Therefore, EHF satellite systems might profitably use antennas that are smaller than those used by the lower frequency counterparts, thus reducing payload weight and cost. This is a further validation of the claim of Sect. I about the capability of EHF of exploiting small-size satellite equipment. For what concerns the earth station, the antenna diameter can be conveniently kept fixed (and large), in order to exploit higher gains to effectively compensate higher distance and atmospheric pathlosses. Being the earth station a fixed or mobile media content distribution center, not seriously impaired by the use of bigger antennas, such solution is acceptable.

However, there is a significant tradeoff to be analyzed, related to the depointing loss. According to [52], the depointing loss can be computed as follows,

$$
L_{p e} \approx 12\left(\frac{\theta \cdot D_{e s} \cdot f_{c}}{65 c}\right)^{2}(d B)
$$

where $\theta$ is the off-boresight angle, expressed in angular degrees. In Fig. 8, the depointing loss has been plotted vs. $\theta$ for the different satellite frequency bands considered in our analysis. $D_{e s}$ has been fixed to 3.5 meters, according to the usual antenna size of broadcasting earth stations. While Ku-band antenna systems are almost immune from depointing, at least for small values of $\theta$, Ka-band counterparts need a more accurate pointing, as a noticeable $3 \mathrm{~dB}$ attenuation is measured for $\theta=0.1^{\circ}$. On the other hand, depointing loss looks very critical for EHF satellite antenna systems, with attenuations values of 9 $\mathrm{dB}$ and $27 \mathrm{~dB}$, occurring for $\theta=0.1^{\circ}$ for the $\mathrm{Q} / \mathrm{V}$ and $\mathrm{W}$-band case respectively. In order to avoid such unpleasant link loss, a very accurate antenna pointing, using highly sophisticated automatically-controlled mechanical systems, must be guaranteed with an off-boresigth angle not exceeding the value of $0.01^{\circ}$. Considering the intrinsic difficulty of assuring such a precise pointing, some small margin will be provided in the link budget in order to cope with residual mismatches due to mechanical and/or control imperfections.

\section{B. Nonlinear amplification and waveform design}

Geostationary satellite systems need power amplifiers characterized by high gain and high Power-Added Efficiency (PAE) (namely: class $C$ amplifiers) [52]. Such requirements become more stringent when EHF links characterized by significant tropospheric link losses are considered. The favored power amplifiers for satellite applications are travelling wave tube amplifiers (TWTAs) or Klystron tubes, characterized by very high saturation power and nonlinear amplification characteristics. Such kind of amplifiers can resort to the linear amplification by applying a large input back off (IBO).

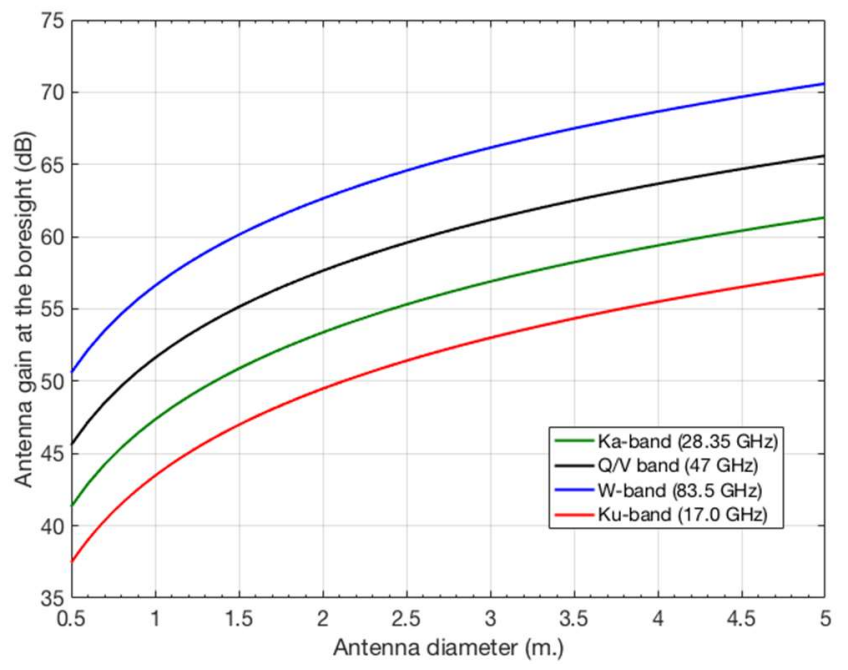

Fig. 7. Transmit antenna gain at the boresight vs. antenna diameter for the different bandwidth consideed in satellite communications.

In Fig. 9, the nonlinear power amplification characteristic curve of a real satellite TWTA working in the $\mathrm{Q} / \mathrm{V}$ band, described in [53], is shown. Linear amplification can be obtained, but at the price of a $10 \mathrm{~dB}$ output back off (OBO). It is clear that the resulting power penalty might be very significant for EHF satellite uplink, where free-space pathloss and atmospheric attenuations are larger than the corresponding ones measured in $\mathrm{Ku}$ and $\mathrm{Ka}$ band. In order to maximally exploit power resources, alternative solutions to IBO insertion should be considered. Distortion compensation methodologies, based on pre-distortion and filtering of out-of-band signal components, like those proposed for DVB-S2, are somewhat complex and hardwareexpensive.

A very attractive solution would concern with the design signaling formats resilient against nonlinear. In such a framework, some papers have been recently published that try to address this issue. Excellent results in terms of resilience against nonlinear distortion have been attained by bi-phase pulse-shaped modulation (PSM) using 1st order Prolate Spheroidal Wave Functions (PSWFs) [54], whose quadriphase version has been proposed in [55] for W-band satellite downlink transmission. $1^{\text {st }}$ and $2^{\text {nd }}$ order PSWF are characterized by reduced sidelobe power level and $1 \mathrm{~dB}$ Peakto-Average-Power Ratio (PAPR). Unfortunately, the practical generation of PSWF is still beyond the capabilities of the currently available hardware. Time-Hopping Impulse Radio (TH-IR) with Gaussian pulses has been proposed in [56] as cost-effective and technically viable alternative solution to PSWF. A general concern about IR solutions is related to the inherently low throughput provided by such techniques that is generally inferior to $2 \mathrm{~b} / \mathrm{s} / \mathrm{Hz}$. However, this reduced spectral efficiency might be acceptable in EHF satellite transmissions, if the robustness against RF and atmospheric impairments is augmented. As we shall see in sect. V, the theoretical capacity of EHF satellite transmission is constrained by lack of power resources and not by lack of bandwidth, so the optimal value of spectral efficiency is generally quite low. 


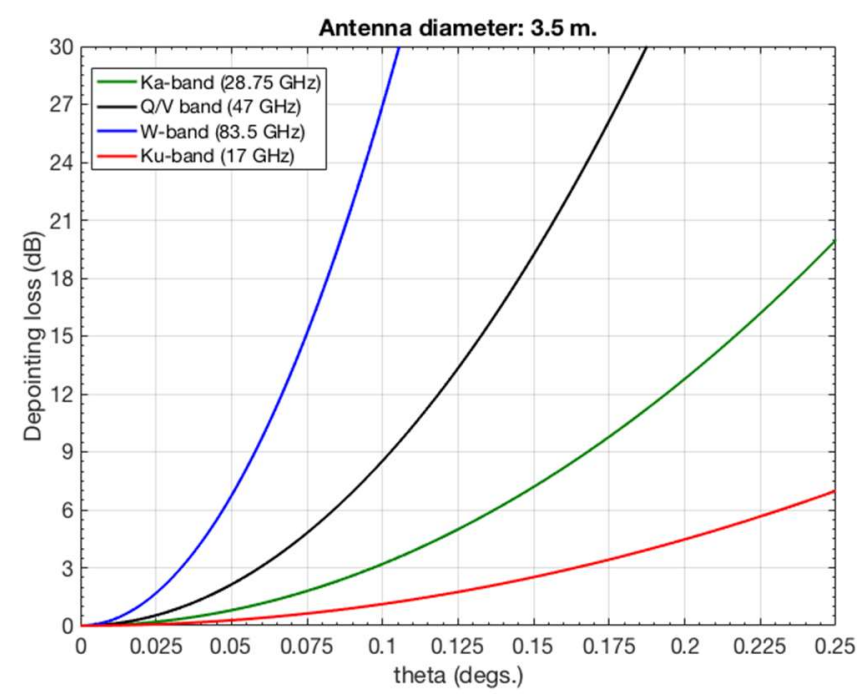

Fig. 8. Depointing loss vs. off-boresight angle (theta) for the different frequency bands used in satellite communications

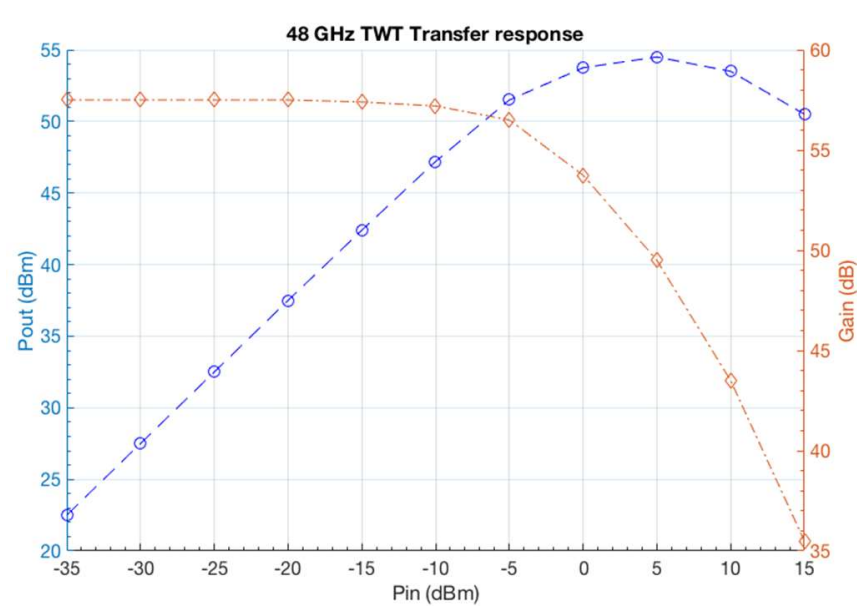

Fig. 9. Example of nonlinear amplifier characteristic curves for a real 48 GHz TWTA

Higher-throughput waveform solutions have been proposed, based on trellis-coded [57] and turbo-coded [58] QAM and PSK modulations with raised-cosine pulse shaping, but they anyway need large OBOs to counteract nonlinear distortions and, as mentioned in the next subsection, are vulnerable to phase noise effects.

Recently, Constant-Envelope multicarrier waveforms, namely: Constant-Envelope Orthogonal Frequency Division Multiplexing (CE-OFDM) [59] and Constant-Envelope SingleCarrier Frequency Division Multiple Access (CE-SCFDMA) [60] have been proposed for downlink terrestrial and satellite communications. CE multicarrier waveforms are implemented by imposing a nonlinear phase modulation to real-valued OFDM and SC-OFDM signals, thus generating a 0dB-PAPR transmitted signal, independently than the adopted modulation constellation. Frequency-domain equalization (FDE) is then applied at the receiver side, before the phase demodulation. Immunity to nonlinear distortion, resilience to phase noise effects, and improved frequency diversity against multipath propagation are achieved by such kind of waveforms [61] [62]. The tradeoff is shown, like for IR waveforms, in terms of reduced spectral efficiency (at least $50 \%$ as compared to conventional OFDM). Moreover, their adaptability to uplink transmission is still an open problem. To sum up, the study of spectrally-efficient and nonlinear distortion-resilient waveforms is an open research field that should carefully consider the specific constraints of EHF satellite environment.

\section{Phase noise}

EHF oscillators are generally characterized by the presence of phase noise that is considerably higher, as compared to that of Ka-band and Ku-band oscillators [7]. Moreover, in a broadcast system, the contribution to system phase noise involved by the use of nonlinear consumer grade Low-Noise Amplifiers (LNAs) and Low-Noise Block converters (LNBs) should be also taken into account [63]. Therefore, phase noise effects cannot not be ignored in the PHY-layer design of EHF broadcast satellite systems. A useful quantity capable of assessing the impact of phase noise in a coherent demodulation system is the residual phase jitter computed as follows [64]:

$$
\phi_{j}=\sqrt{2 \int_{B}^{1 / 2 T} S_{\phi}(\Delta f) d \Delta f} \quad[\mathrm{rad}]
$$

Where $B$ is the carrier recovery loop bandwidth, $T$ is the symbol duration, and $S_{\phi}(\Delta f)$ is the one-sided power spectral density of the overall system phase noise, computed for the frequency shift $\Delta f$, converted from logarithmic scale $(\mathrm{dBc} / \mathrm{Hz})$ to linear scale $\left(\mathrm{rad}^{2} / \mathrm{Hz}\right)$. In [7] some numerical values of $\phi_{j}$ vs. different heights of phase noise masks usually measured in EHF satellite receivers are shown for a baud rate of $500 \mathrm{Mbaud} / \mathrm{sec}$. Such values range from $3.52^{\circ}$ to $19.52^{\circ}$, depending on the mask height. In the literature, it is shown that these jitters may have a critical impact on system performance, even though trellis-coded and turbo-coded modulations are adopted, as done, e.g., in [57] and [58]. Some arrangements aimed at limiting the impact of phase noise may be, therefore, advisable for the downlink. An example of phase noise reduction mechanism for on-ground demodulators in W-band satellite links is proposed in [19], based on frequency extraction and retransmission (FERT). Such mechanism, used in combination with a split-phase Manchester-coded BPSK modulation, is quite effective, as it decreases the on-ground phase noise PSD height of about $15 \mathrm{~dB}$.

In the present paper, the uplink transmission is analyzed. Therefore, we assume that the on-board payload adopts customized components characterized by reduced phase and frequency instability (e.g. Gunn oscillators pointed out in [10]). In the following, appropriate $S N R$ implementation margins will be considered in the link budget in order to take into account the demodulation losses due to phase noise. In particular, we have imposed an implementation margin of $2.5 \mathrm{~dB}$ for the $\mathrm{Q} / \mathrm{V}$ band link, according to the guidelines of Alphasat mission. For what concerns W-band, we adopted the margin of $2.5 \mathrm{~dB}$, considered for the WAVE propagation experiment [10]. As far as Ka-band and $\mathrm{Ku}-$-band links, in absence of specific data, we 
assumed reasonable implementation margins of $2 \mathrm{~dB}$ and 1.5 $\mathrm{dB}$ respectively.

\section{CAPACITY ANALYSIS OF EHF MULTIBEAM SATELLITE SYSTEMS BASED ON SITE DIVERSITY}

\section{A. Analytical capacity formulation}

In this section, we shall formalize the Shannon capacity of multibeam satellite systems exploiting site diversity. The starting point consists of the two equations of power-limited $\left(R_{P}\right)$ and bandwidth-limited $\left(R_{W}\right)$ capacity, considered in [65] to assess the peak data-rate of multibeam satellite systems:

$$
\begin{gathered}
R_{P}(\beta)=\left(\frac{C_{R X}}{N_{0}}\right) \frac{\beta}{2^{\beta}-1} \\
R_{W}(\beta)=\beta K_{b} W_{s b}
\end{gathered}
$$

where:

$$
\beta \triangleq \frac{\rho \log _{2}(M)}{(1+\alpha)}
$$

is the link spectral efficiency (measured in $\mathrm{b} / \mathrm{s} / \mathrm{Hz}$ ), expressed in function of the channel coding rate $\rho$, the number of levels of the modulation constellation $M$, and of the roll-off factor of the adopted waveform $\alpha . C_{R X}$ is the received radio-frequency (RF) carrier power and $N_{0}$ is the power spectral density of the AWGN noise, $W_{s b}$ is the bandwidth to a single beam (namely: a color), and $K_{b}$ is is the number of beams that share the same frequency slot. In case of single-beam transmission $K_{b}=1$. In the considered case of site diversity, $K_{b}$ equals to the number of active gateways. The intersection point between the band-limited capacity curve and the power-limited capacity curve of (8) and (9) provides the achievable peak link capacity and the value of $\beta$ for which such a value is reached. The link budget of the satellite connection is taken into account by the following equation [65], computing the carrier power to noise power spectral density ratio:

$$
\left(\frac{C_{R X}}{N_{0}}\right)=\frac{C_{T X} G_{e s} D_{s a t}^{2} \eta_{e s}}{L_{A} T_{s y s} \gamma M_{i m p}}
$$

where $C_{T X}$ is the radio-frequency transmit power, $G_{e s}$ is the earth-station antenna gain, $D_{\text {sat }}$ the satellite antenna diameter, $\eta_{a}$ is the equivalent surface efficiency of the earth-station antenna. At the denominator of (9), $L_{A}$ represents the global tropospheric attenuation, including the gaseous absorption and the rain fading, while $T_{s y s}$ is the noise temperature of the satellite terminal (in ${ }^{\circ} \mathrm{K}$ ), $M_{i m p}$ is the $S N R$ implementation margin, mainly related to MO-DEM implementation losses, involved by the presence of phase noise as mentioned in subsection IV.C. and, finally $\gamma=3.6377 \cdot 10^{-7} \mathrm{~J} \cdot \mathrm{m}^{2} / \mathrm{K}$ incorporates the Boltzmann constant and the squared power of the distance GEO satellite-earth station (the maximum value of such a distance is assumed $40580 \mathrm{Km}$, corresponding to antenna elevation of $10 \mathrm{deg}$.).

When a multi-beam satellite system is employed (like in the site diversity implementation), the power-limited capacity expression should be corrected as follows,

$$
R_{P}(\beta)=\max \left\{0,\left(\frac{C_{R X}}{N_{0}}\right) \frac{\beta}{2^{\beta}-1}-\beta\left(\frac{I}{N_{0}}\right)\right\}
$$

where $I$ is the total power of the interfering beams. It is evident that the achievable data rate of (10) is not only limited by the carrier power-to noise spectral density ratio, but also depends from the carrier power to beam interference ratio $C_{R X} / I$, whose expression is reported in the following:

$$
C_{R X} / I=\frac{g\left(\varphi_{i i}\right)}{\sum_{\substack{j=1 \\ j \neq i}}^{J} g\left(\varphi_{i j}\right)}
$$

where $g(\varphi)$ is the normalized antenna gain, expressed as a function of the generic beam angle $\varphi, \varphi_{i j}$ is the angle (expressed in radians) that forms the satellite receiver $i$ towards the spot beam $j$ sharing the same frequency (if $j \neq i$ the beam $j$ interferes with the beam $i$. Ideally, $\varphi_{i i} \approx 0$ ).

It can be easily verified that, if $\beta>\log _{2}\left[\left(C_{R X} / I\right)+1\right]$, the values of $R_{p}$ become negative. This means that the multibeam transmission system is dominated by the interference and, therefore, it is impossible to achieve any data rate without errors in the decoded bits. Under such conditions, the concept of Shannon capacity no longer holds and, consequentially, $R_{p}$ is set to 0 .

The value of $C_{R X} / I$ is strictly related to the adopted multibeam satellite receive antenna and to the transmission frequency. In this paper, we consider the Single Feed per Beam Network (SFBN) antenna model with combined transmission and reception antennas [66] that has been already assessed in some state-of-the-art contributions about multibeam satellite systems [67], [68]. In particular, the normalized antenna gain vs. the beam angle $\varphi$ is given as follows,

$$
\begin{aligned}
& g(\varphi)=2 \Delta(p, \Gamma) \frac{J_{1}\left(\frac{\pi D_{a} \sin (\varphi)}{\lambda}\right)}{\left(\frac{\pi D_{a} \sin (\varphi)}{\lambda}\right)}+ \\
& +2^{p+1} \Delta(p, \Gamma) p ! \frac{\Gamma}{1-\Gamma} \frac{J_{p+1}\left(\frac{\pi D_{a} \sin (\varphi)}{\lambda}\right)}{\left(\frac{\pi D_{a} \sin (\varphi)}{\lambda}\right)^{p+1}}
\end{aligned}
$$

where $p$ is the aperture plan, $\Gamma$ is the aperture edge taper, $D_{a}$ is the antenna diameter, $\lambda$ is the signal wavelength, $J_{p}$ is the Bessel function of the first kind of order $p$ and, finally,

$$
\Delta(p, \Gamma)=\frac{(p+1)(1-\Gamma)}{(p+1)(1-\Gamma)+\Gamma}
$$

Using the parameterization of [67], [68], i.e.: $p=2$ and $\Gamma=0.9$, the curves of $g(\varphi)$ plotted in Fig.10 are obtained for the 
different satellite frequency bands considered in our paper. According to what stated in section IV.A, the diameter of satellite receive antennas has been set to $1.0 \mathrm{~m}$ for $\mathrm{W}$ and $\mathrm{Q} / \mathrm{V}$ band and $1.5 \mathrm{~m}$ for $\mathrm{Ka}$ and $\mathrm{Ku}$-band respectively. It can be observed that the W-band SFBN multibeam antenna, despite the reduced diameter, exhibits a stronger capability of cochannel interference rejection thanks to the narrower $3 \mathrm{~dB}$ beamwidth. On the other hand, the $\mathrm{Q} / \mathrm{V}$ band antenna and the larger Ka-band antenna attain quite similar performance $(\mathrm{Q} / \mathrm{V}$ band antenna performing slightly better). On the other hand, the $\mathrm{Ku}$-band antenna suffers from a much larger main radiation lobe and, for this reason, we should expect a reduced immunity to inter-beam interference in case of aggressive frequency reuse.

\section{B. Numerical capacity evaluation}

This subsection is devoted at analyzing the raw peak capacity (computed in the previous subsection) attained by EHF satellite systems, compared with that achieved by state-of-the-art satellite systems working in $\mathrm{Ka}$ and $\mathrm{Ku}$ band. The following scenarios have been considered:

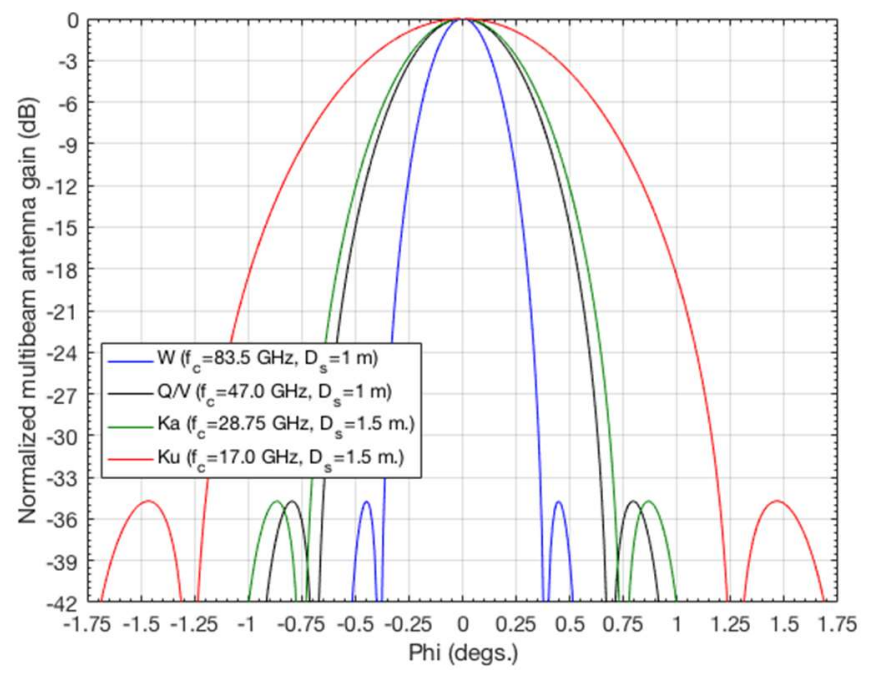

Fig. 10. Angular radiation pattern of the SFBN multibeam satellite receive antenna used in [67-68] for the different satellite transmission bandwidths.

- Clear-sky single-beam transmission without site diversity: this is the usual operative scenario for most of broadcast TV satellite systems. Results related to this scenario are shown in Fig. 11;

- Single beam transmission without site diversity, in presence of tropospheric attenuation (rain and clouds). In this scenario, we consider a capacity value available for $99.9 \%$ of the operational service time. Results related to this scenario are shown in Fig. 12;

- $\quad$ Site diversity in presence of tropospheric attenuation and ideal beam insulation. In such a scenario, we are considering an ideal multibeam satellite system where $C_{R X} / I=+\infty$. Also in this scenario, we consider a capacity value available for $99.9 \%$ of the operational service time. Results related to this scenario are shown in Fig. 13;

- $\quad$ Site diversity in presence of tropospheric attenuation and non-ideal beam insulation. In such a case, we consider the presence of inter-beam interference, modeled as in subsection V.A, considering the SBFN antenna, whose radiation pattern has been shown in Fig. 10. For coherency with the rest of the analysis, $99.9 \%$ availability has been considered also in this scenario, whose related results are shown in Fig. 14.

The results of Figures 11 to 14 have been obtained by parameterizing the capacity expressions of subsection V.A on the basis of the geographical locations of the active gateways, listed in Tab. II, and the numerical values provided by the link budget shown in Tab. III. The values of $C / I$, listed in the last row of Tab. III, have been derived by using the SFBN antenna model of [66] with beam angles computed according to the mathematical procedure shown in [69], which is based on the geographical locations of the active gateways.

TABLE II. GEOGRAPHICAL LOCATION OF THE ACTIVE GATEWAYS

\begin{tabular}{|c|l|c|c|}
\hline Gateway N. & Site & $\begin{array}{c}\text { Lon } \\
\text { (deg.) }\end{array}$ & $\begin{array}{c}\text { Lat } \\
\text { (deg.) }\end{array}$ \\
\hline 1 & Cork (IR) & $8.48 \mathrm{~W}$ & $51.89 \mathrm{~N}$ \\
\hline 2 & Rambouillet (FR) & $01.46 \mathrm{E}$ & $48.32 \mathrm{~N}$ \\
\hline 3 & Turin (IT) & $07.68 \mathrm{E}$ & $45.07 \mathrm{~N}$ \\
\hline 4 & Ljubljana (SI) & $14.50 \mathrm{E}$ & $46.15 \mathrm{~N}$ \\
\hline 5 & Berlin (DE) & $13.20 \mathrm{E}$ & $52.30 \mathrm{~N}$ \\
\hline 6 & Scanzano (IT) & $13.36 \mathrm{E}$ & $37.91 \mathrm{~N}$ \\
\hline 7 & Helsinki (SF) & $24.94 \mathrm{E}$ & $60.17 \mathrm{~N}$ \\
\hline 8 & Athens (GR) & $23.73 \mathrm{E}$ & $37.98 \mathrm{~N}$ \\
\hline 9 & Budapest (HU) & $19.00 \mathrm{E}$ & $47,38 \mathrm{~N}$ \\
\hline 10 & Madrid (ES) & $03.44 \mathrm{~W}$ & $40.30 \mathrm{~N}$ \\
\hline 11 & Cyprus (CY) & $33.38 \mathrm{E}$ & $34.86 \mathrm{~N}$ \\
\hline 12 & London (GB) & $00.30 \mathrm{E}$ & $51.30 \mathrm{~N}$ \\
\hline
\end{tabular}

In Fig. 11, the peak capacity is evaluated in the clear sky scenario without site diversity and single beam transmission. In such a case the W-band transmission is advantaged, as it provides a peak capacity of $77 \mathrm{Gbps}$, by a spectral efficiency of $7.7 \mathrm{~b} / \mathrm{s} / \mathrm{Hz}$. W-band transmission outperforms the other considered bandwidths, because it can exploit a higher antenna gain, as compared to that of $\mathrm{Q} / \mathrm{V}$ band, and, in addition, wider bandwidth availability as compared to $\mathrm{Ka}$ and $\mathrm{Ku}$ bands.

When tropospheric attenuations (rain and clouds) impair the link, the situation dramatically changes, at clearly shown in Fig. 12. In such a case, Ka-band provides the best performance in terms of capacity $(18.1 \mathrm{Gbps}$, with corresponding spectral efficiency of $6.1 \mathrm{~b} / \mathrm{s} / \mathrm{Hz}$ ) and $\mathrm{Ku}$-band performs quite closer (17 Gbps). On the other hand, transmission in EHF bands is severely hindered by tropospheric attenuation, with negligible capacity values of few gigabits/sec. In any case, the capacity reduction is very significant for all the considered bandwidths. If the site diversity-based arrangement, described in Section III, is considered to exploit the full potential of broadband satellite communications, we obtain a great capacity improvement for all the assessed transmission bands. Such an improvement is due both to the diversity gain and to the multibeam transmission that works as spatial multiplexer. This is clearly shown in Fig. 13, where the case of ideal beam insulation is analyzed. In such a theoretical scenario, $\mathrm{Q} / \mathrm{V}$ band slightly outperforms the other frequency bands, but the achieved capacity values are rather similar. In Fig. 14, the technically meaningful scenario of multibeam site diversity with non-ideal beam insulation is finally considered. In such a last case, EHF bands provides almost the same capacities (153 Gbps for W-band and $155 \mathrm{Gbps}$ 
for $\mathrm{Q} / \mathrm{V}$ band) that is doubled as compared to that of Ka-band and almost 5 times than that offered by Ku-band. In this real scenario, it is shown how the use of Q/V-band and W-band can actually support UHDTV transmission of hundreds of channels and multimedia services foreseen in the next decade, while Kaband can effectively support less than one hundred of UHDTV channels. To sum up, we can claim that site diversity allows to EHF bands to exploit their full potential in terms of augmented bandwidth availability, converted into useful capacity. In the comparative assessment, if we assume that W-band and Q/V bands can exploit the same bandwidth amount - as imposed by the current frequency allocation plans - the winner of the competition seems the $\mathrm{Q} / \mathrm{V}$ band, thanks to the reduced impact of atmospheric attenuations. But, in the future, we should expect that the frequency availability of W-band could increase, thanks to the exploitation of the bandwidth portions around 94 $\mathrm{GHz}$ (that has been already forecasted by DAVID-DCE experiment [10]). If such unexplored bandwidth spaces would become available for satellite transmission, the picture might change again.

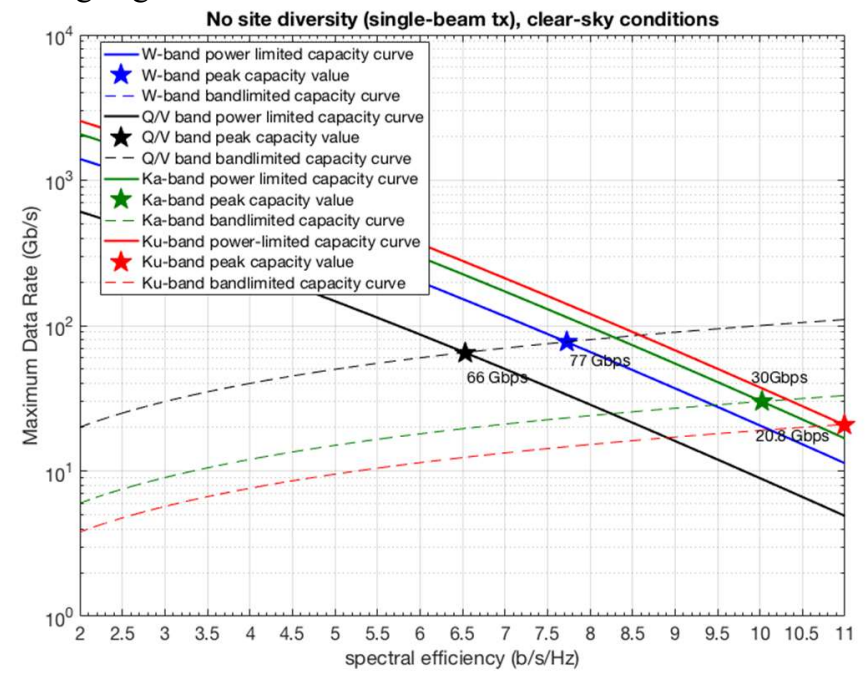

Fig. 11. Capacity curves and peak data rates obtained in clear sky conditions and without site diversity.

\section{EHF FOR CURRENT AND FUTURE HIGH-DEFINITION TV SATELLITE SERVICES}

Raw capacity results shown in Section IV suggest that EHF may offer very favorable opportunities in terms of multigigahertz bandwidth availability, provided that suitable countermeasures against tropospheric attenuations (like smart gateway diversity) will be studied and developed. Moreover, it has to be underlined that the very high-throughputs provided by the use of EHF require the development of very-high speed receivers, whose actual implementation is beyond the scope of this paper.

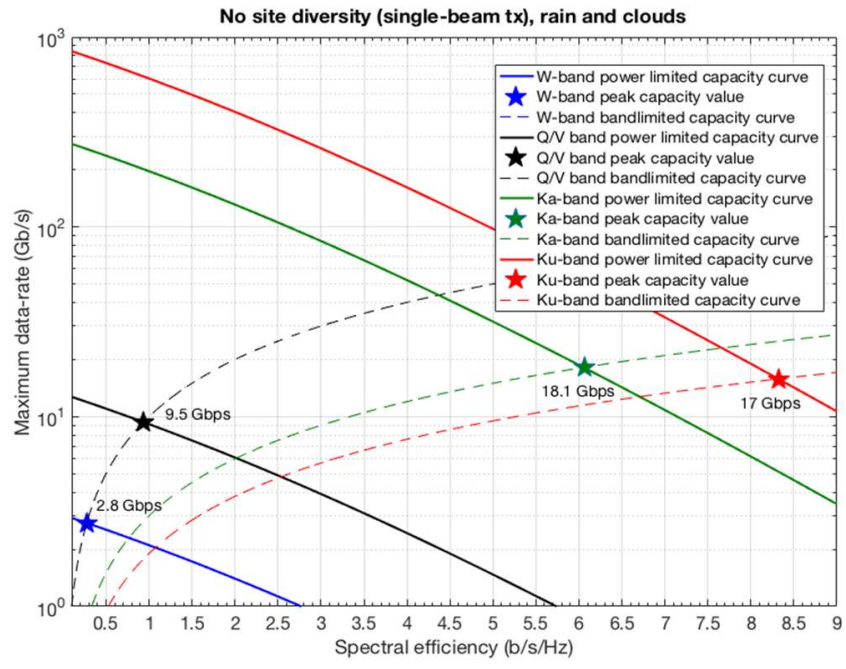

Fig. 12. Capacity curves and peak data rates obtained in presence of tropospheric attenuation (rain and clouds) and without site diversity.

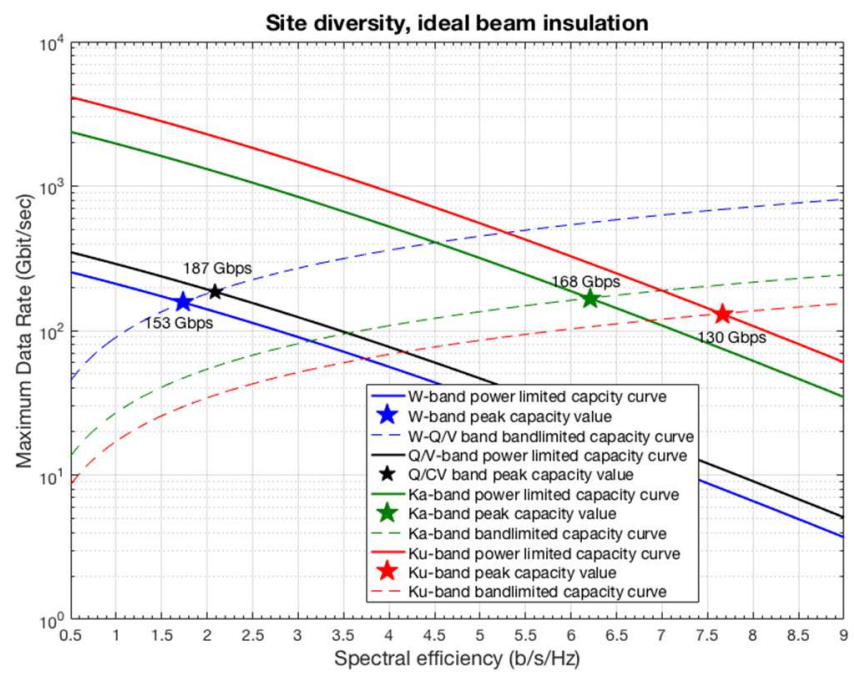

Fig. 13. Capacity curves and peak data rates obtained in presence of tropospheric attenuation (rain and clouds) with site diversity and ideal beam insulation.

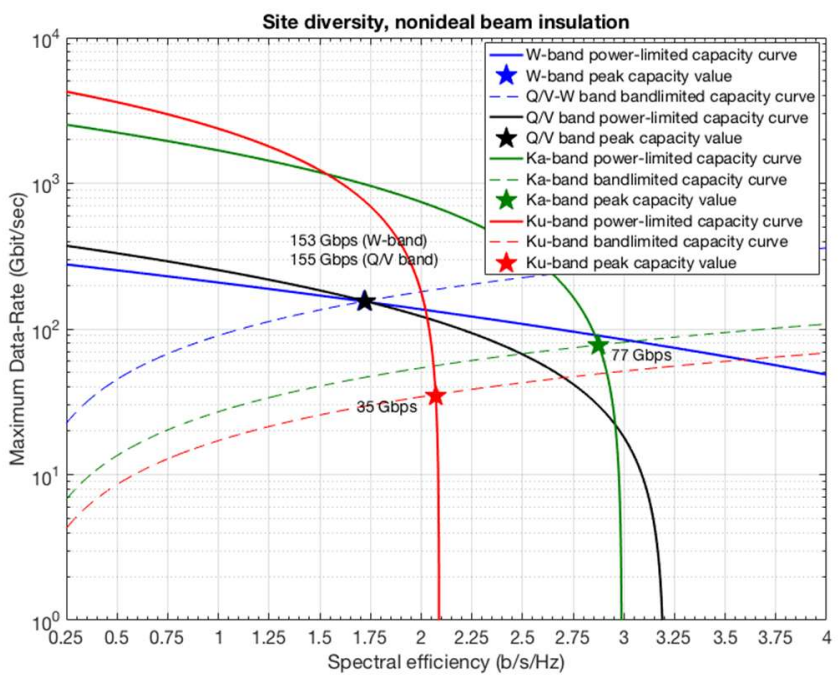

Fig. 14. Capacity curves and peak data rates obtained in presence of tropospheric attenuation (rain and clouds) with site diversity and nonideal beam insulation (SFBN antenna employed for multibeam transmission). 
TABLE III. EXAMPLE OF LINK BUDGET EMPLOYED FOR CAPACITY EVALUATION

\begin{tabular}{|c|c|c|c|c|c|c|}
\hline \multirow[t]{2}{*}{ Item } & \multicolumn{3}{|c|}{ Value } & \multirow{2}{*}{ Ku-band } & \multirow[t]{2}{*}{ Units } & \multirow[t]{2}{*}{ Notes } \\
\hline & W-band & Q/V-band & Ka-band & & & \\
\hline Up-link central frequency & 83.5 & 47 & 28.75 & 17.0 & $\mathrm{GHz}$ & \\
\hline Available bandwidth (feeder link) & 10 & 10 & 3 & 1.9 & $\mathrm{GHz}$ & Dual polarization \\
\hline Down-link central frequency & 19.2 & 19.2 & 19.95 & 12.0 & $\mathrm{GHz}$ & \\
\hline Available bandwidth (user link) & 4 & 4 & 1 & 1 & $\mathrm{GHz}$ & Dual polarization \\
\hline User Beam Bandwidth & 1000 & 1000 & 250 & 150 & $\mathrm{MHz}$ & $\begin{array}{l}\text { Ka-band / Dual } \\
\text { polar. Four } \\
\text { Colors }\end{array}$ \\
\hline Single carrier bandwidth & 60 & 60 & 60 & 60 & $\mathrm{MHz}$ & $\begin{array}{c}\text { Two 8K channels } \\
\text { (at first } \\
\text { approximation) }\end{array}$ \\
\hline N.er of carriers per user beam & 16 & 16 & 4 & 2 & & $\begin{array}{l}\text { Considering } \\
\text { band-guard }\end{array}$ \\
\hline N.er of carriers per $\mathrm{GW}$ & 160 & 160 & 48 & 30 & $\mathrm{MHz}$ & \\
\hline N.er of active GWs (nominal) & 9 & 9 & 9 & 9 & & \\
\hline Tx Antenna diameter & 3.5 & 3.5 & 3.5 & 3.5 & $\mathrm{M}$ & \\
\hline Tx Antenna efficiency & 0.6 & 0.6 & 0.7 & 0.7 & & \\
\hline Tx power & $\begin{array}{c}22.78(4 \\
\text { TWTA, each } \\
150 \text { W @ } \\
\text { saturation, with } \\
5 \text { dB OBO) }\end{array}$ & $\begin{array}{c}24.03 \text { (4 } \\
\text { TWTA, each } \\
200 \text { W @ } \\
\text { saturation, with } \\
5 \text { dB OBO) }\end{array}$ & $\begin{array}{l}28 \text { (4 TWTA, } \\
\text { each 250 W @ } \\
\text { saturation,with } \\
2 \text { dB OBO) }\end{array}$ & $\begin{array}{c}30 \text { (TWTA } \\
\text { inclusive of } \\
\text { OBO) }\end{array}$ & dBW & \\
\hline Tx Pointing Loss & 1.5 & 1 & 0.5 & 0.1 & $\mathrm{~dB}$ & \\
\hline Tx Polarization Loss & 0 & 0 & 0 & 0 & $\mathrm{~dB}$ & \\
\hline Slant range & 40000 & 40000 & 40000 & 40000 & $\mathrm{Km}$ & \\
\hline Atmospheric loss & 30 & 20 & 12 & 5 & $\mathrm{~dB}$ & $\begin{array}{c}99.9 \% \\
\text { Availability }\end{array}$ \\
\hline Diversity Gain & 20 & 15 & 10 & 4.5 & $\mathrm{~dB}$ & $\begin{array}{c}99.9 \% \\
\text { Availability }\end{array}$ \\
\hline Rx Antenna diameter & 1 & 1 & 1.5 & 1.5 & $\mathrm{M}$ & \\
\hline Rx Antenna efficiency & 0.6 & 0.6 & 0.7 & 0.7 & & \\
\hline Rx cable loss & 0 & 0 & 0 & 0 & $\mathrm{~dB}$ & \\
\hline Rx pointing loss & 1 & 1 & 0.5 & 0.5 & $\mathrm{~dB}$ & \\
\hline RX Noise Figure & 3.0 & 3.0 & 2.5 & 1.8 & $\mathrm{~dB}$ & \\
\hline Operating Temperature & 290 & 290 & 290 & 290 & $\mathrm{~K}$ & \\
\hline Receive Bandwidth & 1000 & 1000 & 250 & 150 & $\mathrm{MHz}$ & \\
\hline Rx Antenna Temperature & 290 & 290 & 290 & 290 & $\mathrm{~K}$ & \\
\hline Rx Feeder Attenuation & 0.5 & 0.5 & 0.5 & 0.5 & $\mathrm{~dB}$ & \\
\hline Rx Feeder Temperature & 3 & 3 & 3 & 3 & $\mathrm{~K}$ & \\
\hline $\mathrm{C} / \mathrm{N}_{0}$ downlink & 92 & 92 & 92 & 92 & $\mathrm{dBHz}$ & \\
\hline $\mathrm{C} / \mathrm{N}_{0}$ total & 88.23 & 89.16 & 91.85 & 91.86 & $\mathrm{dBHz}$ & \\
\hline Useful bandwidth per carrier & 54.55 & 54.55 & 54.55 & 54.55 & $\mathrm{MHz}$ & 0.1 roll-off \\
\hline Actual Es/ $/ \mathrm{N}_{0}$ & 10.86 & 11.80 & 14.49 & 14.49 & $\mathrm{~dB}$ & \\
\hline DVB-S2X ModCod & 16APSK 2/3-L & 16APSK 13/18 & 32APSK 11/15 & 32APSK 11/15 & & \\
\hline ModCod Spectral efficiency & 2.63 & 2.85 & 3.62 & 3.62 & Bit/symb. & \\
\hline ModCod Es $/ \mathrm{N}_{0}$ requirement (standard) & 8.43 & 9.71 & 12.17 & 12.17 & $\mathrm{~dB}$ & $\begin{array}{c}\text { Quasi Error Free } \\
\text { FER }=10^{-5}\end{array}$ \\
\hline MO-DEM implementation loss & 2.5 & 2.5 & 2 & 1.5 & $\mathrm{~dB}$ & \\
\hline $\mathrm{C} / \mathrm{I}$ (nonideal beam insulation case) & 20.57 & 9.14 & 8.41 & 5.13 & $\mathrm{~dB}$ & SFBN antenna \\
\hline
\end{tabular}

In this section and in the following ones, we shall analyze how current and future satellite broadcast services can benefit from the new bandwidth resource that can be found in the EHF spectrum portions. As a matter of fact, the two largest drivers of satellite revenues are broadband connectivity and video broadcasting. In the near future these two markets will increase due to some important observations: launch costs are decreasing due to aerospace industries that are currently developing low cost space transportation services; moreover, the satellite will remain a very cost-effective mean to reach a large number of customers, in particular if we think about emerging markets mainly made by people spread over large territories (where the density is much lower than urban areas).
In this framework, it is of paramount importance to exploit the new EHF technologies in the next generations of broadcasting satellite systems.

\section{A. HDTV services}

Broadcast TV services can exploit the large bandwidth portions available in the EHF domain in order to exponentially increment the offering of regular TV and High-Definition TV (HDTV) channels. The reduced link availability due to rain fading can be effectively contrasted by optimized settings of coding and modulation parameters. In their recent work [70], Morel et. al. studied the adaptability of Variable Coding Modulation (VCM) and Adaptive Coding Modulation (ACM) techniques conceived for DVB-S2 standard to future 
broadcasting services. In VCM, different video qualities are transmitted employing different modulation and coding parameters time-sharing each physical layer frame.

As contrast, ACM adaptively transmits the best video quality on the basis of specific feedback about channel conditions. The main outcome of the analysis of [70] is that ACM provides advantages for very small beam sizes and against annual propagation variations; moreover, ACM supports another potential commercial driver, enabling the re-use of the same satellite payload architecture both for broadband access interactive services or broadcast satellite services [70].

However, VCM, used in Ka-band, provides the best performance in terms of number of delivered channels and does not require feedback. As EHF satellites are generally characterized by small beam sizes and the annual propagation variations may be considerable, ACM is best tailored for providing high quality broadcast services in $\mathrm{Q} / \mathrm{V}$ and $\mathrm{W}$-bands. We think that the advantages yielded by ACM well compensate the increase of complexity required by the need of a feedback channel. In [21], the optimal thresholds for the available DVBS2 ACM modes have been discussed for W-band communication. Nonlinear distortion compensation has been adopted in [21] and estimated time series for rain attenuation have been considered in simulations. The thresholds have been completely reformulated and some ACM methods indicated in the DVB-S2 standard have been suppressed. This reformulation yielded to a significant performance improvement with respect to the conventional DVB-S2 ACM parameterization, with a substantial increment of the link availability. In a more recent work [17], some of the authors of [21] proposed a similar analysis of optimal ACM parameters and thresholds for the $\mathrm{Q} / \mathrm{V}$ band. In particular, it has been demonstrated, for the $\mathrm{Q} / \mathrm{V}$ band case, the possibility of improving the ACM performance by using hysteresis technique with respect to the classical fixed threshold method.

A different kind of study has been proposed by Fantinato et. al. in [22], where the end-to-end DVB-S2 HDTV video broadcasting transmission at $76 \mathrm{GHz}$ has been simulated in SIMULINK environment in the presence of nonlinear distortion, phase noise and with rain attenuation simulated by means of the estimated time series of [21]. The quality of the received HDTV videos has been assessed by means of the Structural Similarity Index Metric (SSIM), highly correlated to the human visual perception. Results shown in [22] are fully convincing about the effectiveness of ACM in contrasting rain fading and improving service availability, with a fully satisfactory visual quality (SSIM $>0.95)$ for at least $95 \%$ of the rain event duration.

\section{B. Ultra High-Definition TV (UHDTV) applications}

If TV and HDTV services are the "present" of broadcast mass-market, the (near) future will be represented by UHDTV services, capable of offering to residential customers unprecedented resolution rates, namely: 4K (3840x2160 pixels) and $8 \mathrm{~K}$ (7680x4320 pixels) [71]. This latter, known also as Super Hi-Vision (SHV), will offer a superior feeling of "presence" and convey more convincing impression of reality. As a matter of fact, it is expected that UHDTV will become a mass market in the next decade. Moreover, many tests on UHDTV transmission are currently conducted by satellite operators together with the launch on the customer market of some $4 \mathrm{~K}$ channels (most of them are tailored on very important sport events).

However, also unprecedented bit-rates should be supported for this kind of signals, namely: $10.6 \mathrm{~Gb} / \mathrm{s}$ for $4 \mathrm{~K}$ and $72 \mathrm{~Gb} / \mathrm{s}$ for $8 \mathrm{~K}$ [72]. It had been clear that H.264 coding, successfully adopted for HDTV videos, was not appropriate to encode such a large volume of video contents. Video coding adopted for SHV is the High Efficiency Video Coding (HVEC) standard [72], conceived in order to provide efficient compression of broadband $4 \mathrm{~K}$ and $8 \mathrm{~K}$ signals, while preserving a satisfactory perceived video quality.

The data rates produced by $8 \mathrm{~K}$ HVEC encoders are very high as compared to those of conventional HDTV H.264 encoders. Depending on the typology of sequences, the main tier of the coding should be transmitted at a bit-rate ranging from $60 \mathrm{Mb} / \mathrm{s}$ to $165.5 \mathrm{Mb} / \mathrm{s}$ [23]. As far as quality parameters are concerned, the bit-error-rate (BER) requirement for SHV transmission is $10^{-12}$, while latency should be much less than the period of the video frames $\left(1 / 60^{\text {th }}\right.$ of second for SHV) [71].

The use of EHF, in particular "beyond Ka-band", can actually support this kind of connectivity, exploiting the large portion of the spectrum available at these frequencies to allocate a very large number of $4 \mathrm{~K} / 8 \mathrm{~K}$ UHDTV channels. At a first approximation, a $35 \mathrm{MHz}$ satellite channel can be used to transmit an $8 \mathrm{~K}$ signal at 120 fps with a payload rate of about $100 \mathrm{Mbps}$ and symbol rate of about $35 \mathrm{Mbaud} / \mathrm{sec}$. By 2025 more than 800 UHDTV channels are foreseen, in this framework, Ka-band satellite transmission can no longer be a solution and $\mathrm{Q} / \mathrm{V}$-band or $\mathrm{W}$-band are required to support UHDTV connectivity. Moreover, a very important challenge in UHDTV live transmission of sporting, news gathering and other events, is the development of transportable satellite mobile units; in this context, the smaller RF equipment dimension of millimetre-wave (w.r.t. lower frequencies), provides the opportunity to increase the transportability of the mobile units (i.e. very small antennas).

\section{Numerical evaluation of UHDTV channels availability}

Quantitative results about the mapping of the raw capacity into numbers of available UHDTV channels have been shown in the bar plot of Fig. 15. Such results have been obtained by assuming a bit-rate of $118 \mathrm{Mb} / \mathrm{s}$, for each coded SHV channel, a raised-cosine waveform with roll-off 0.1 , according to the UHDTV satellite transmission experiment of [23]. Moreover, a guard band of $7 \mathrm{MHz}$ has been introduced in order to separate each channel multiplexed in FDM modality. In Tab. IV, the theoretical spectral efficiency values $\beta_{\text {theore }}$, maximizing the raw capacity in Figs. 11 to 14, have been mapped into coded modulation constellations actually used in DVB-S2 standard (the throughput of DVB-S2 coded modulation modes ranges from $0.5 \mathrm{~b} / \mathrm{s} / \mathrm{Hz}$ to $4.5 \mathrm{~b} / \mathrm{s} / \mathrm{Hz}$ [49][50]). We used the real spectral efficiency of DVB-S2 constellations in order to compute the bandwidth of each transmitted SHV channels. The two most significant scenarios have been considered in this last assessment, i.e.: single beam transmission without site diversity in the presence of tropospheric attenuations (Fig. 12), and multi beam transmission supporting site diversity with non-ideal beam insulation (Fig. 14), respectively. 
Results shown in Fig. 15 dramatically evidence the benefits of the exploitation of site diversity for UHDTV broadcasting in the EHF domain. Using site diversity, the broadcasting system fully exploits the larger bandwidth availability of EHF bands, also in presence of tropospheric attenuations (rain and clouds), increasing the spectral efficiency with respect to the singlebeam case and offering a number of SHV channels that is 2 times and almost 5 times that offered by Ka-band and $\mathrm{Ku}$-band respectively. On the contrary, the tropospheric attenuations impair a lot the EHF link when no site diversity is employed. In such a case, the largest number of available SHV channels is offered by Ka-band. It should be noticed that site diversity is beneficial also for $\mathrm{Ka}$ and $\mathrm{Ku}$ band satellite systems. Indeed, the number of supported SHV channels is anyway superior to that provided by the single-beam configuration. However, such increment is limited by the impact of inter-beam interference that consistently reduces the spectral efficiency with respect to the single-beam case. The adoption of multi-beam detection techniques [68] [73] may partially change this picture, but the price to be paid in terms of on-board computational burden might be relevant.

TABLE IV. THEORETICAL VALUES OF SPECTRAL EFFICIENCY AND REAL CODED MODULATION FORMATS OF DVB-S2 STANDARD

\begin{tabular}{|c|c|c|c|}
\hline Scenario & $\begin{array}{c}\text { Frequency } \\
\text { band }\end{array}$ & $\begin{array}{c}\beta_{\text {theore }} \\
(\mathrm{b} / \mathrm{s} / \mathrm{Hz})\end{array}$ & $\begin{array}{l}\text { DVB-S2 mod-cod } \\
\text { mode }\end{array}$ \\
\hline \multirow{4}{*}{$\begin{array}{l}\text { No site diversity / } \\
\text { tropospheric } \\
\text { attenuations (Fig. } \\
12 \text { ) }\end{array}$} & W-band & 0.2 & None available \\
\hline & $\mathrm{Q} / \mathrm{V}$ band & 0.94 & $\begin{array}{l}\text { QPSK with code } \\
\text { rate } 1 / 2\end{array}$ \\
\hline & Ka-band & 6.05 & $\begin{array}{c}\text { 32-APSK with } \\
\text { code-rate } 4 / 5\end{array}$ \\
\hline & $\mathrm{Ku}$-band & 8.3 & $\begin{array}{c}\text { 32-APSK with } \\
\text { code-rate } 4 / 5\end{array}$ \\
\hline \multirow{4}{*}{$\begin{array}{l}\text { Site diversity / non } \\
\text { ideal beam } \\
\text { insulation (Fig. 14) }\end{array}$} & W-band & 1.68 & $\begin{array}{l}\text { 8-PSK with code- } \\
\text { rate } 3 / 5\end{array}$ \\
\hline & $\mathrm{Q} / \mathrm{V}$ band & 1.7 & $\begin{array}{c}\text { 8-PSK with code- } \\
\text { rate } 3 / 5\end{array}$ \\
\hline & Ka-band & 2.88 & $\begin{array}{c}\text { 16-APSK with } \\
\text { code-rate } 3 / 4\end{array}$ \\
\hline & Ku-band & 2.08 & $\begin{array}{l}\text { 8-PSK with code- } \\
\text { rate } 2 / 3\end{array}$ \\
\hline
\end{tabular}

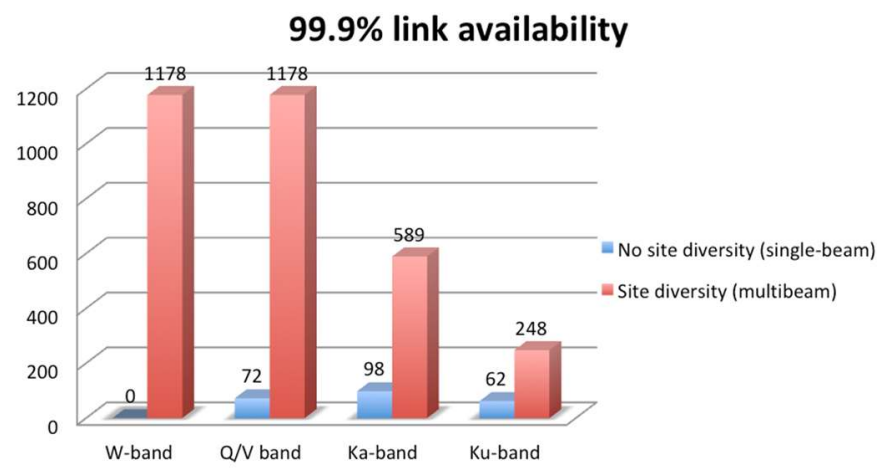

Fig. 15. Number of SHV channels available in the different frequency bands, considering the presence of tropospheric attenuations and using the DVB-S2 coded modulation formats: single-beam transmission without site diversity and multibeam transmission with site diversity (nonideal beam insulation).

\section{CONCLUSION}

In this paper, opportunities and challenges inherent to the utilization of Extremely Higher Frequency (EHF) bands for future broadcast and multimedia services have been explored. In the near future, HTS architectures can be used to provide flexible regionalized contents tailored on customer base.

The "raw" capacity analysis evidenced the full potential of $\mathrm{Q} / \mathrm{V}$ and $\mathrm{W}$ band for multi-gigabit multi-beam satellite connections, thanks to the higher antenna gains, the wider bandwidth availability and the intrinsic capability of rejecting multi-beam interference. However, adequate countermeasures against rain fading should be considered in order to avoid unexpected capacity pitfalls (Adaptive Coding and Modulation, smart gateways, etc.). As soon as the EHF broadband "raw" capacity is available, the conversion of many potential gigabaud/sec (or $\mathrm{GHz}$ ) of capacity into information gigabit/sec throughput is not given for grant. Accurate physical layer design is required in order to avoid unpleasant effects of RF hardware impairments (linear and nonlinear distortions, phase noise). The analysis of commercial services that can exploit EHF bandwidths evidences great benefits achievable by broadcast TV, in particular HDTV/UHDTV services and multimedia content delivery foreseen for the next decade can be effectively supported using these frequencies; this last with attractive possibilities of integration with $5 \mathrm{G}$ terrestrial networking. Interesting perspectives are also expectable for Internet of Remote Things (IoRT) and TCP/IP-based services, provided that suitable architectures and higher-layer networking techniques will be proposed and developed. This will be matter for future research work.

\section{REFERENCES}

[1] Satellite Communications \& Broadcasting Markets Survey: Forecasts to 2026, Report, Euroconsult, Sept. 2017.

[2] M. Anedda, A. Meloni, M. Murroni, "64-APSK constellation and mapping optimization for satellite broadcasting using genetic algorithms," IEEE Transactions on Broadcasting, vol. 62, no. 1, pp. 1-9. March 2016.

[3] G Taricco, A Ginesi, "Precoding for Flexible High Throughput Satellites: Hot-Spot Scenario," to appear in IEEE Transactions on Broadcasting, DOI: 10.1109/TBC.2018.2847438

[4] G. Cocco, T. De Cola, M. Angelone, Z. Katona, S. Erl, "Radio Resource Management Optimization of Flexible Satellite Payloads for DVB-S2 Systems," IEEE Transactions on Broadcasting, vol. 64, no. 2, 266-280, June 2018

[5] C. Niephaus, J. Mödeker and G Ghinea, "Toward Traffic Offload in Converged Satellite and Terrestrial Networks," to appear in IEEE Transactions on Broadcasting, DOI: 10.1109/TBC.2018.2863124.

[6] $8 \mathrm{~K}$ Super Hi-Vision available online at http://www.nhk.or.jp/8k/index_e.html

[7] E. Cianca, T. Rossi, A. Yahalom, Y. Pinhasi, J. Farserotu, and C. Sacchi, "EHF for satellite communications: The New Broadband Frontier," Proc. IEEE, vol. 99, no.11, pp. 1858-1881, Nov. 2011.

[8] B. G. Evans, P. T. Thompson, G. E. Corazza, A. Vanelli-Coralli and E. A. Candreva, "1945-2010: 65 Years of Satellite History From Early Visions to Latest Missions," Proc. IEEE, vol. 99, no. 11, pp. 1840-1857, Nov. 2011.

[9] M. Ruggieri, S. De Fina, M. Pratesi, A. Salomè, E. Saggese, C. Bonifazi, "The W-band Data Collection Experiment of the DAVID Mission", IEEE Trans. on AES, vol. 38, no. 4,pp. 1377-1387, Oct. 2002.

[10] M. Lucente, T. Rossi, M. Ruggieri, A. Jebril, A. Iera, A. Molinaro, S. Pulitanò, C. Sacchi, L. Zuliani, "Experimental Missions in W-Band: a Small LEO Satellite Approach", IEEE Systems Journal, vol.2, no.1, pp. 90-103, Mar. 2008. 
[11] T. Rossi, M. De Sanctis, F. Maggio, G. Codispoti, G. Parca, "Q/V-band Satellite Communication Experiments on Channel Estimation with Alphasat Aldo Paraboni P/L," Proc. of 2016 IEEE Aerospace Conf., Big Sky, MT, March 2016.

[12] T. Rossi, M. De Sanctis, M. Ruggieri, C. Riva, L. Luini, C. Codispoti, E. Russo, G. Parca "Satellite Communications and Propagation Experiments through the Alphasat $\mathrm{Q} / \mathrm{V}$ band Aldo Paraboni Technology Demonstration Payload," IEEE AES Magazine, pp. 18-26, March 2016.

[13] P. Thompson, B. Evans, M. Bousquet, L. Castanet and T. Mathiopoulos, "Concept and Technologies for a Terabit/s Satellite," Proc. of 2011 IARIA SPACOMM Conf., Budapest (H), April 17-22 2011, pp. 12-19.

[14] F. Gargione, T. Iida, F. Valdoni and F. Vatalaro, "Services, technologies, and systems at Ka band and beyond-a survey," IEEE Journal on Selected Areas in Communications, vol. 17, no. 2, pp. 133-144, Feb 1999.

[15] M. De Sanctis, E. Cianca, T. Rossi, C. Sacchi, L. Mucchi and R. Prasad, "Waveform Design Solutions for EHF Broadband Satellite Communications," IEEE Comm. Mag., pp. 18-23, March 2015.

[16] T. Rossi et al., "Experimental assessment of optimal ACM parameters in Q/V-band satellite communication," 2016 IEEE Aerospace Conference, Big Sky, MT, 2016, pp. 1-10.

[17] T. Rossi, M. De Sanctis, D. Di Mattia, and M. Ruggieri, "Performance Analysis and Optimization of Site Diversity Techniques for EHF Satellite Links," 2011 IEEE Aerospace Conf., Big Sky, MT, March 2011, pp. 111.

[18] A. Kyrgiazos, B. G. Evans, and P. Thompson, "On the gateway diversity for high throughput broadband satellite systems," IEEE Transactions on Wireless Communications, vol. 13, no. 10, pp. 5411-5426, Oct 2014.

[19] C. Sacchi, G. Gera, and C. Regazzoni, "Wband Physical Layer Design Issues in the Context of the DAVID-DCE Experiment", Int. Jour. of Satellite Communications and Networking, vol. 22, no. 2,pp. 193-215, March-April 2004.

[20] T. Rossi, M. De Sanctis and F. Maggio, "Evaluation of Outage Probability for Satellite Systems Exploiting Smart Gateway Configurations," IEEE Communications Letters, vol. 21, no. 7, pp. 1541-1544, July 2017.

[21] S. Mukherjee, M. De Sanctis, T. Rossi, E. Cianca, M. Ruggieri and R. Prasad, "On the optimization of DVB-S2 links in EHF bands," 2010 IEEE Aerospace Conference, Big Sky, MT, 2010, pp. 1-11.

[22] A. Fantinato, N. Conci, T. Rossi and C. Sacchi, "Performance analysis of W-band satellite HDTV broadcasting," 2011 Aerospace Conference, Big Sky, MT, 2011, pp. 1-12.

[23] K. Oyamada, S. Okabe, K. Aoki and Y. Suzuki, "Progress of Transmission Technologies for UDTV," Proc. IEEE, vol. 101, no. 1, pp. 154-168, Jan. 2013.

[24] N. Mandolesi, "Balloon-borne measurements of the atmospheric emission near 94 GHz", Journal of Atmospheric and Solar-Terrestrial Physics, vol. 60, no. 4, pp. 71-80, 1998.

[25] N.C. Currie, C.E. Brown, Principles and Applications of Millimeter-Wave Radar, Artech House, 1987.

[26] A. Nordbotten, "LMDS systems and their application," IEEE Communications Magazine, vol. 38, no. 6, pp. 150-154, Jun 2000.

[27] T. S. Rappaport et al., "Millimeter Wave Mobile Communications for 5G Cellular: It Will Work!," in IEEE Access, vol. 1, pp. 335-349, 2013.

[28] C. Sacchi, T. F. Rahman, I. A. Hemadeh and M. El-Hajjar, "MillimeterWave Transmission for Small-Cell Backhaul in Dense Urban Environment: a Solution Based on MIMO-OFDM and Space-Time Shift Keying (STSK)," IEEE Access, vol. 5, pp. 4000-4017, 2017.

[29] W. Bocquet, "Perspectives on the study of Millimeter Waves Bands for the Deployment of 5G," Study workshop on using mm-waves bands for the deployment of the $5 G$ ecosystem in the Union, Brussels (B), June 2018, $\mathrm{http}$ available at: https://ec.europa.eu/digital-single-market/en/news/

[30] IEEE Standard for Information technology--Telecommunications and information exchange between systems--Local and metropolitan area networks-Specific requirements-Part 11: Wireless LAN Medium Access Control (MAC) and Physical Layer (PHY) Specifications Amendment 3 : Enhancements for Very High Throughput in the $60 \mathrm{GHz}$ Band," in IEEE Std 802.11 ad-2012 (Amendment to IEEE Std 802.11-2012, as amended by IEEE Std 802.11ae-2012 and IEEE Std 802.11aa-2012), vol., no., pp.1628, Dec. 282012.

[31] K.H. Laudan, "MmWave Bands for 5G", Study workshop on using mmwaves bands for the deployment of the $5 G$ ecosystem in the Union,
Brussels (B), June 2018, http available at: https://ec.europa.eu/digitalsingle-market/en/news/.

[32] R. Polonio and C. Riva, "ITALSAT propagation experiment at 18.7, 39.6 and $49.5 \mathrm{GHz}$ at Spino D'Adda: three years of CPA statistics," IEEE Trans. on Antennas and Propagat., vol. 46, no. 5, pp. 631-635, May 1998.

[33] G. Codispoti. G. Parca, M. Ruggieri, T. Rossi, M. De Sanctis, C. Riva, L. Luini, "The role of the Italian Space Agency in investigating high frequencies for satellite communications: The Alphasat experiment," Int $J$ Satell Commun Network, May 2018, pp. 1-10, early view available at: https://doi.org/10.1002/sat.1252.

[34] J. A. Haulund and R. Khullar, "Advanced Extremely High Frequency mission planning: Will its legacy dictate its future?," 2012 IEEE First AESS European Conference on Satellite Telecommunications (ESTEL), Rome, 2012, pp. 1-5.

[35] M. Sarchet, "AEHF Update," Presentation to AFCEA Los Angeles Chapter, Los Angeles (CA), 22 March 2012, http available at: https://afcea-la.org/

[36] A. Jebril et al., "The WAVE mission payload," 2005 IEEE Aerospace Conference, Big Sky, MT, 2005, pp. 903-912.

[37] H. Fenech, S. Amos, A. Tomatis and V. Soumpholphakdy, "High throughput satellite systems: An analytical approach," in IEEE Transactions on Aerospace and Electronic Systems, vol. 51, no. 1, pp. 192-202, January 2015.

[38] H. Hemmati, A. Biswas and I. B. Djordjevic, "Deep-Space Optical Communications: Future Perspectives and Applications," Proc. IEEE, vol. 99, no. 11, pp. 2020-2039, Nov. 2011.

[39] Y. Arimoto, M. Toyoshima, M. Toyoda, T. Takahashi, M. Shikatani, and K. Araki, "Preliminary result on laser communication experiment using (ets-vi)," in Free-Space Laser Communication Technologies VII, vol. 2381. International Society for Optics and Photonics, 1995, pp. 151-159.

[40] T. Tolker-Nielsen and G. Oppenhauser, "In-orbit test result of an operational optical intersatellite link between artemis and spot4, silex," in Free-Space Laser Communication Technologies XIV, vol. 4635. International Society for Optics and Photonics, 2002, pp. 1-16.

[41] E. Cianca, T. Rossi, M. Ruggieri, M. Presi, E. Ciaramella, L. Luini, C. Sacchi, G. Parca, and G. Codispoti, "Softwarization and Virtualization as enablers for Future EHF/FSO High Throughput Satellites," in Proc. of IEEE Globecom 2018 Conf., Abu Dhabi (UAE), Dec. 9-13, 2018.

[42] L. J. Ippolito, "Radio propagation for space communication systems," Proc. IEEE, vol. 69, no. 6, pp. 697-727, Jun. 1981.

[43] “Attenuation by atmospheric gases,” Rec. ITU-R P.676-3, 1997.

[44] Rec. ITU-R P.838-2, Specific attenuation model for rain for use in prediction methods (Question ITU-R 201/3), http available at: https://www.itu.int/dms_pubrec/itu-r/rec/p/R-REC-P.838-2-200304S!!PDF-E.pdf, 2003.

[45] Rec. ITU-R P.839-4, Rain height model for prediction methods (Question ITU-R 201/3), http available at: https://www.itu.int/dms_pubrec/itur/rec/p/R-REC-P.839-4-201309-I!!PDF-E.pdf, 2013.

[46] P. Mandarini, Comunicazioni Elettriche, Ingegneria 2000 ed., Roma (Italy): 1989 (in Italian).

[47] Rec. ITU-R P.840-7, "Attenuation due to clouds and fog," http available at: https://www.itu.int/dms_pubrec/itu-r/rec/p/R-REC-P.840-7-201712I!!PDF-E.pdf, 12/2017.

[48] F. S. Marzano and C. Riva, "Cloud-induced effects on monthly averaged scintillation amplitude along millimeter-wave slant paths," in IEEE Transactions on Antennas and Propagation, vol. 51, no. 4, pp. 880-887, April 2003.

[49] DVB-S2 Standard, ETSI EN 302 307-1 V1.4.1 (2014-11).

[50] DVB-S2X Standard extension, Draft ETSI EN 302 307-2 V1.1.1 (2014$10)$.

[51] S. Andrenacci, D. Spano, D. Christopoulos, S. Chatzinotas, J. Krause and B. Ottersten, "Optimized link adaptation for DVB-S2X precoded waveforms based on SNIR estimation," 2016 50th Asilomar Conference, Pacific Grove, CA, 2016, pp. 502-506.

[52] Handbook on Satellite Communications, 3rd ed. New York: Wiley, 2002, International Telecommunication Union (ITU).

[53] A. Katz, R. Gray and R. Dorval, "Linearizers for Q- and V-Band TWTAs," IEEE Transactions on Electron Devices, vol. 65, no. 6, pp. 2371-2377, June 2018. 
[54] D. Slepian, and H.O. Pollack "Prolate Spheroidal Wave Functions, Fourier Analysis and Uncertainty", I. Bell System Tech. J., vol. 40, pp. 4364, 1961.

[55] C. Sacchi, T. Rossi, M. Ruggieri, F. Granelli, "Efficient Waveform Design for High-Bit-Rate W-band Satellite Transmissions", IEEE Trans. on AES, Vol. 47, no. 2, pp. 974-995, Apr. 2011.

[56] M. De Sanctis, C. Sacchi, E. Cianca and T. Rossi, "Impulse-radio waveforms for MM-wave satellite communications: Potential benefits and open issues," 2016 10th European Conference on Antennas and Propagation (EuCAP), Davos, 2016, pp. 1-5.

[57] C. Sacchi and A. Grigorova, "Use of Trellis-Coded Modulation for Gigabit/sec Transmissions over W-Band Satellite Links", 2006 IEEE Aerospace Conference, Big Sky, MT, March 2006.

[58] B.H. Tabor, C. Sacchi, and C. Schlegel, "Spectrally-efficient Differential Turbo-coded Modulation for Multi-gigabit Satellite Links," 2013 IEEE Aerospace Conference, Big Sky, MT, March 2013.

[59] S. C. Thompson, A. U. Ahmed, J. G. Proakis, J. R. Zeidler, and M. J. Geile, "Constant Envelope OFDM," IEEE Transactions on Communications, vol. 56, no. 8, pp. 1300-1312, Aug. 2008.

[60] R. Mulinde, T. F. Rahman and C. Sacchi, "Constant-envelope SC-FDMA for nonlinear satellite channels," 2013 IEEE Global Communications Conference (GLOBECOM), Atlanta, GA, 2013, pp. 2939-2944.

[61] C. Sacchi, E. Cianca, T. Rossi and M. De Sanctis, "Analysis and assessment of the effects of phase noise in constant envelope multicarrier satellite transmissions," 2015 IEEE International Conference on Communications (ICC), London, 2015, pp. 922-927.

[62] T. F. Rahman, C. Sacchi, S. Morosi, A. Mazzinghi and N. Bartolomei, "Constant-Envelope Multicarrier Waveforms for Millimeter Wave 5G Applications," IEEE Transactions on Vehicular Technology, vol. 67, no.10, pp. 9406-9420, Oct. 2018.

[63] H. Ohnishi, M. Makimoto and K. Feher, "Spectrally efficient digital broadcast systems operated in a phase noise environment," IEEE Transactions on Broadcasting, vol. 35, no. 1, pp. 31-39, March 1989.

[64] J.K. Holmes, “Coherent Spread Spectrum Systems," Wiley, Chicester (UK): 1984.

[65] J.D. Gayrard, "Terabit Satellite: Myth or Reality?," Proc. of 2009 IEEE SPACOMM Conf., Colmar (F), July 20-25 2009, pp. 1-6.

[66] R. E. Collin, Antennas and Radiowave Propagation, McGraw-Hill, New York: 1989.

[67] R. Alegre-Godoy, M.A. Vazquez-Castro, and L. Jiang, "Unified Multibeam Satellite System Model for Payload Performance Analysis," in Proc. of 3rd Int. Conf. on Personal Satellite Services (PSATS 2011), Malaga (Spain), Feb. 2011, pp. 365-377.

[68] C. Stallo and C. Sacchi, "Link performance analysis of multi-user detection techniques for W-band multi-beam satellites," 2016 IEEE Aerospace Conference, Big Sky (MT), March 2016, pp. 1-9.

[69] W. Zheng, B. Li, S. Ren, J. Chen, and J. Wu, "Interference modeling and analysis for inclined projective multiple beams of geo satellite communication systems,", Proc. of 2012 2nd International Conference on Computer and Information Application (ICCIA 2012), Dec. 2012, pp. 535-538.

[70] C. Morel, P. D. Arapoglou, M. Angelone and A. Ginesi, "Link Adaptation Strategies for Next Generation Satellite Video Broadcasting: A System Approach," IEEE Transactions on Broadcasting, vol. 61, no. 4, pp. 603614, Dec. 2015.

[71] G. J. Sullivan, J. R. Ohm, W. J. Han and T. Wiegand, "Overview of the High Efficiency Video Coding (HEVC) Standard," IEEE Transactions on Circuits and Systems for Video Technology, vol. 22, no. 12, pp. 16491668, Dec. 2012.

[72] D. Zhou et al., "An 8K H.265/HEVC Video Decoder Chip With a New System Pipeline Design," IEEE Journal of Solid-State Circuits, vol. 52, no. 1, pp. 113-126, Jan. 2017.

[73] G. Colavolpe, A. Modenini, A. Piemontese and A. Ugolini, "Multiuser Detection in Multibeam Satellite Systems: Theoretical Analysis and Practical Schemes," IEEE Transactions on Communications, vol. 65, no. 2, pp. 945-955, Feb. 2017.

Claudio Sacchi (M'01-SM'07) received the "Laurea" Degree in Electronic Engineering, and the Ph.D. in Space Science and Engineering at the University of Genoa (Italy) in 1992 and 2003, respectively. From 1996 to 2002, he has been research cooperator with the University of Genoa, Dept. of Biophysical

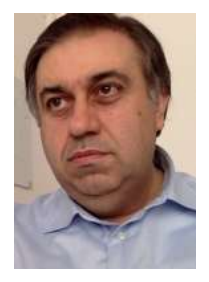

and Electronic Engineering (DIBE) and with the National Italian Consortium in Telecommunications (CNIT), managing project activities in the field of multimedia surveillance systems and satellite communications. Since August 2002, Dr. Sacchi is assistant professor at the Department of Information Engineering and Computer Science (DISI) of the University of Trento (Italy). Claudio Sacchi is author and co-author of more than 100 papers published in international journals and conferences. In 2011, he was guest editor of the special issue of PROCEEDINGS OF THE IEEE: "Aerospace Communications: History, Trends and Future." Moreover, in 2015, he was guest editor of the featured-topic special issue of IEEE COMMUNICATIONS MAGAZINE: "Toward the Space 2.0 Era." Dr. Sacchi has been invited lecturer to international PhD Summer schools. He also held seminars and short courses both for MSc and PhD students in recognized EU and North American Universities and research institutions. The research interests of Dr. Sacchi are mainly focused on wideband mobile and satellite transmission systems based on space, time and frequency diversity; MIMO systems; array processing; multi-rate and multi-access wireless communications; EHF broadband aerospace communications; software radio and cognitive radio; radio communications for emergency recovery applications. Claudio Sacchi is a senior member of IEEE and a member of the IEEE ComSoc, IEEE Broadcast, IEEE VT and IEEE AESS society.

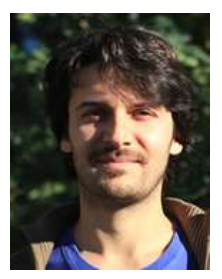

Tommaso Rossi Assistant Professor of Telecommunications Engineering (teaching Digital Signal Processing, Multimedia Processing and Communication and Signals) at the University of Rome Tor Vergata. His research activity is focused on Space Systems, EHF Satellite and Terrestrial Telecommunications, Satellite and Inertial Navigation Systems, Digital Signal Processing for Radar and TLC applications, use of millimeter-waves for Medical Imaging applications. He is currently Co-Investigator for the Italian Space Agency of the Q/V-band (40/50 $\mathrm{GHz}$ ) communication experiments realized through the Aldo Paraboni payload on-board Alphasat satellite. He is Associate Editor for the Space Systems area of the IEEE Transactions on Aerospace and Electronic Systems. He authored more than 80 papers published on journals and conference proceedings.

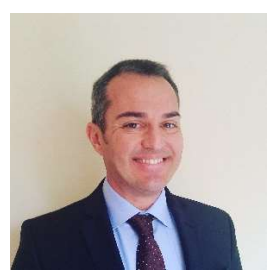

Maurizio Murroni (SM'13) received a M.Sc. degree in Electronic Engineering in 1998 and a Ph.D. degree in Electronic Engineering and Computers in 2001 from the University of Cagliari. He was graduate visiting scholar at the School of Electronic Engineering, Information Technology and Mathematics, University of Surrey, Guildford, U.K. in 1998 and a visiting Ph.D. scholar at the Image Processing Group, Polytechnic University, Brooklyn, NY, USA, in 2000. In 2006 and 2014, he was visiting lecturer at the Dept. of Electronics and Computers at the Transilvania University of Brasov in Romania and in 2011 visiting professor at the Dept. Electronics and Telecommunications, Bilbao Faculty of Engineering, University of the Basque Country (UPV/EHU) in Spain. Currently, is associate professor at the Department of Electrical and Electronic Engineering (DIEE) of the University of Cagliari. Since October 2011, he is coordinator of the research unit of the Italian University Consortium for Telecommunications (CNIT) at the University of Cagliari. Since 2016 is chair of the IEEE Broadcast Technology Society Italy chapter. He is distinguished lecturer for the IEEE Broadcast Technology Society and associate editor for the IEEE Transactions on Broadcasting. Dr. Murroni is co-author of an extensive list of journal articles and peer-reviewed conference papers and received several best paper awards. He served as chair for various international conferences and workshops while he was guest editor for several journals. He was co-author of the 1900.6-2011 IEEE Standard for Spectrum Sensing Interfaces and Data Structures for Dynamic Spectrum Access and other Advanced Radio Communication Systems. His research currently focuses on quality of experience, multimedia data transmission and processing, broadcasting, cognitive radio system, signal processing for radio communications. Dr. Murroni is senior member of the Institute of Electrical and Electronic Engineering (IEEE), IEEE ComSoc, IEEE BTS, IEEE VTS, IEEE SPS.

Marina Ruggieri (S'84-M'85-SM'94-F'14) Full Professor in Telecommunications Engineering at University of Roma "Tor Vergata" (Italy) and therein: member of the Board of Directors; Chair of the President's Advisory Committee for the relationship with the Italian Space Agency (ASI); 


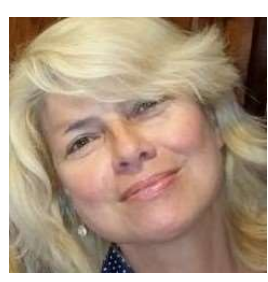

Steering Board Chair of CTIF, an Interdisciplinary Research Center on Information and Communications Technology and its verticals. She has been: Vice President with responsibility of the ASI Technical and Scientific Council and member of the Research Policy Experts Advisory Committee of the University and Research Ministry. She is the Principal Investigator of the $40 / 50 \mathrm{GHz}$ Communications Experiment on-board ESA Alphasat satellite, launched in 2013. She is arbitrator of the Italian Industries Federation for Aerospace, Defense and Security. She has been Vice President of the AFCEA Rome Chapter (2006-2015). She has been IEEE 2017 Vice President, Technical Activities; 2014-2015 Director of IEEE Division IX; 2010-2011 President of the IEEE Aerospace and Electronic Systems Society (AESS). She is 2019-2021 member of the AESS Board of Governors and AESS Officer. She received: 1990 P. Fanti International Prize; 2009 Pisa Donna Award; Excellent/Best Paper Awards at international conferences; 2011 AESS Service Award; 2013 Excellent Women in Roma Award. She has been inducted as a Professional into the Honor Society of IEEE Eta Kappa Nu (HKN). She is IEEE Fellow "for contributions to millimeter-wave satellite communications". She authored 335 papers, 1 patent and 12 books. 